\title{
Hydrogen-Bonded Rosettes of Aminotriazines for Selective-lon Recognition
}

\author{
Andre N. Petelski ${ }^{\dagger, \ddagger}$ and Célia Fonseca Guerra* ${ }^{* \dagger, \S_{\odot}}$ \\ ${ }^{\dagger}$ Department of Theoretical Chemistry and Amsterdam Center for Multiscale Modeling, Vrije Universiteit Amsterdam, De Boelelaan \\ 1083, 1081HV Amsterdam, The Netherlands \\ *Departamento de Ingeniería Química, Grupo de Investigación en Química Teórica y Experimental (QuiTEx), Facultad Regional \\ Resistencia, Universidad Tecnológica Nacional, French 414 (H3500CHJ), Resistencia, Chaco, Argentina \\ ${ }^{\S}$ Leiden Institute of Chemistry, Gorlaeus Laboratories, Leiden University, Einsteinweg 55, 2333CD Leiden, the Netherlands
}

Supporting Information

ABSTRACT: Ion recognition is still an emerging topic in supramolecular chemistry and has aroused great attention in the last few years. In this work, we have examined the assemblies of selected hexameric rosettes of melamine and ammeline and their capacities to host halide and alkali ions in the gas phase and in water. Using relativistic dispersion-corrected density functional theory (DFT-D), we first studied the stability and the effect of introducing monovalent anions $\left(\mathrm{Cl}^{-}, \mathrm{Br}^{-}\right.$, and $\left.\mathrm{I}^{-}\right)$and cations $\left(\mathrm{Na}^{+}, \mathrm{K}^{+}\right.$, and $\left.\mathrm{Rb}^{+}\right)$in the center of the rosette's cavity. Finally, we explored the interactions in two stacked rosettes with an interlayer ion. Our computations reveal that aminesubstituted triazines are promising candidates for anion and cation recognition either in self-assembled monolayers or pillar array structures. The anion recognition process is governed by both the electrostatic and charge-transfer (donor-acceptor) interactions, while the cation recognition is governed by electrostatic and polarization. In addition, melamine and ammeline could constitute a potent mixture for dual-ion recognition strategies.

\section{INTRODUCTION}

Noncovalent synthesis is an elegant approach in supramolecular chemistry to construct highly complex structures with well-defined properties. $^{1-3}$ Their strategies require a fundamental understanding of molecular interactions as well as the thermodynamics of the process. Thus, by manipulating and tuning intermolecular forces, chemists could master the controlled design of new materials. This is why the physicochemical information about structural issues and interaction properties, which can be obtained by theoretical calculations, constitutes a valuable background for experimentalists. $^{4,5}$

An emerging topic in the field of supramolecular chemistry is the use of cyclic rosette complexes ${ }^{6-9}$ to build large structures. In this context, 1,3,5-triazine-2,4,6-triamine or melamine (M), which is also very well-known for its uses in the plastic industry, ${ }^{10}$ has been considered a very versatile building block for creating a great diversity of sophisticated functional materials. ${ }^{11}$ Their rosettes can stack on top of each other to form one dimensional wires or columnar arrays ${ }^{12,13}$ and three dimensional network structures. ${ }^{14-16}$ Besides, self-assembled monolayers of $\mathrm{M}$ and some related compounds over $\mathrm{Au}(111)^{17-21}$ and highly oriented pyrolytic graphite ${ }^{22-24}$ surfaces have also been obtained and characterized. These materials could have potential applications in the functionalization of surfaces, ${ }^{25}$ hydrogels, ${ }^{26,27}$ noncovalent polymers, and nanoelectronics. $^{28}$
On the other hand, it is known that the presence of ions induces a change on the hydrogen-bonding pattern, ${ }^{29,30}$ and they can assist the self-assembly process. ${ }^{31-34}$ For instance, guanine (G) molecules self-assemble in quartets by the inclusion of a $\mathrm{K}^{+}$cation in the center. ${ }^{35,36}$ They can also form the well-known G-quadruplexes (GQ), which are arranged by three stacked layers of G-quartets with cations in between. Even more, Kotlyar et al. ${ }^{37}$ have obtained long Gwires, with and without potassium cations in between, envisaging promising applications in nanoelectronics. However, when it comes to anions, there are just a few examples in the literature about anion recognition by supramolecules. The first cases in this context are the adenine quartets, which were shown to coordinate $\mathrm{F}^{-}, \mathrm{Cl}^{-}$, and $\mathrm{Br}^{-38,39}$ Then, Paragi et al. ${ }^{40}$ have proposed with theoretical predictions that 7-methylguanine cyclic rings are also able to coordinate anions such as $\mathrm{Cl}^{-}, \mathrm{Br}^{-}$, and $\mathrm{NO}^{3-}$.

In a previous work on aminotriazine rosettes, we have shown that ammeline (AM) has a greater self-assembling capability than melamine $(M) .^{41}$ This is because of a stronger pair interaction and the fact that the AM rosette experiences a considerable synergetic effect. In this work, we investigated if $\mathrm{M}$ or AM can coordinate ions in the same way as GQ and G-

Received: October 4, 2019

Revised: November 10, 2019

Published: November 11, 2019 
Scheme 1. Molecular Structures of M Rosettes ${ }^{a}$
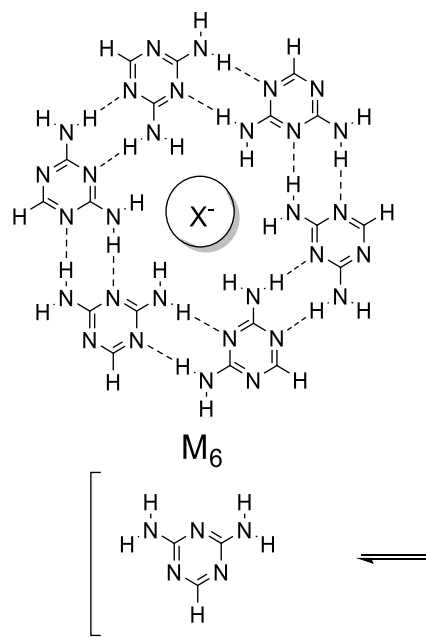

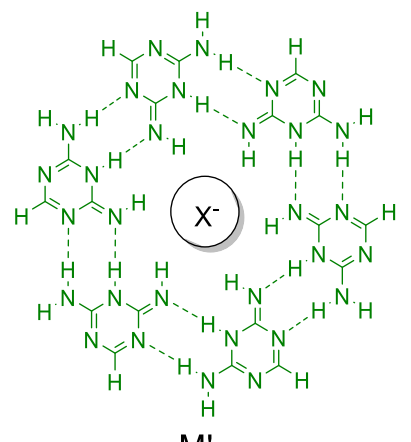

$\mathrm{M}_{6}$

H H H

$H^{N_{N}}{ }_{N_{Y}^{N}}^{N_{Y}^{N}}$

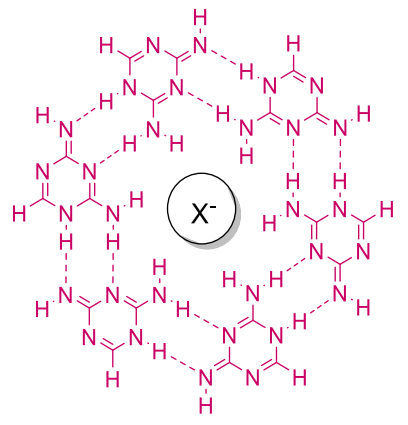

$\mathrm{M}_{6}$

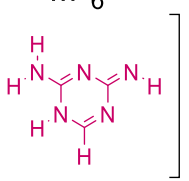

${ }^{a} \mathrm{X}^{-}=\mathrm{Cl}^{-}, \mathrm{Br}^{-}, \mathrm{I}^{-}$.

wires coordinate cations. With this aim, we have explored a model set of seven rosette-like supramolecules, ${ }^{41}$ as shown in Schemes 1 and 2 and their interactions with various monovalent anions $\left(\mathrm{Cl}^{-}, \mathrm{Br}^{-}\right.$, and $\left.\mathrm{I}^{-}\right)$as well as cations $\left(\mathrm{Na}^{+}, \mathrm{K}^{+}\right.$, and $\left.\mathrm{Rb}^{+}\right)$. The computations are based on dispersion-corrected density functional theory (DFT-D). Our investigations cover the situation of single rosettes and stacked

Scheme 2. Molecular Structures of AM Rosettes ${ }^{a}$

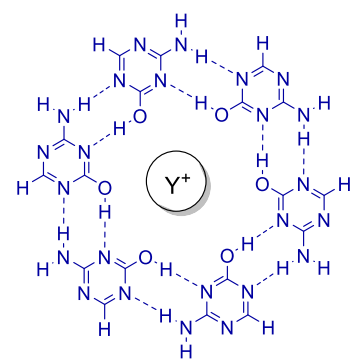

a- $\mathrm{AM}_{6}$

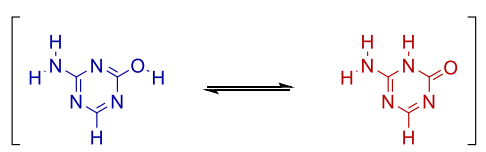

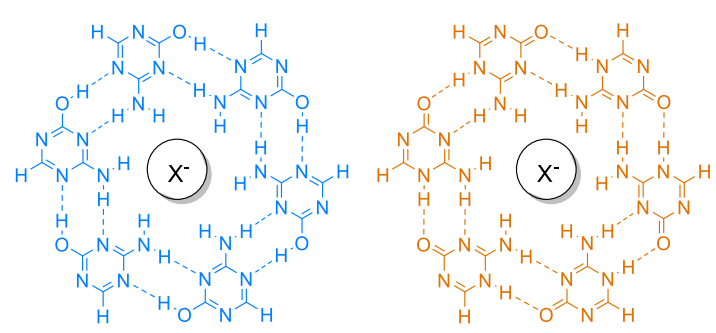

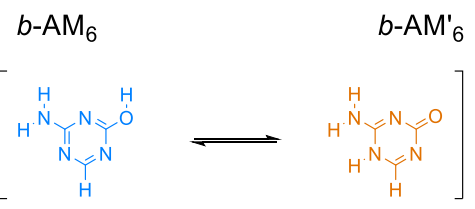

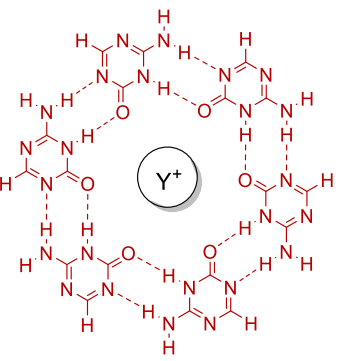

a- $\mathrm{AM}_{6}$

${ }^{a} \mathrm{Y}^{+}=\mathrm{Na}^{+}, \mathrm{K}^{+}, \mathrm{Rb}^{+}$and $\mathrm{X}^{-}=\mathrm{Cl}^{-}, \mathrm{Br}^{-}, \mathrm{I}^{-}$.

complexes. In both cases, we also consider conditions in the gas phase and aqueous solution.

\section{COMPUTATIONAL METHODS}

All calculations were performed by using the Amsterdam Density Functional (ADF) program developed by Baerends et al., ${ }^{42,43}$ based on dispersion-corrected relativistic density functional theory at the ZORA-BLYP-D3(BJ)/TZ2P level for geometry optimizations and energies, which has been shown to reproduce hydrogen bond strengths and structures accurately. ${ }^{38,39}$ The basis set superposition error was not computed because this effect was proved to be small (less than $1 \mathrm{kcal}$ $\mathrm{mol}^{-1}$ ) for the chosen basis set in similar systems. ${ }^{44}$ In order to mimic either a surface environment or a stacking arrangement, a planar symmetry $\left(C_{2 h}\right)$ was imposed on the rosettes. This approach provides also a clear $\sigma-\pi$ separation, which is more informative. The stacked systems were optimized with $C_{2}$ symmetry enforced.

Solvent effects ${ }^{45-47}$ have been estimated using the conductor-like screening model ${ }^{38,48-50}$ (COSMO) for water, as implemented in the $\mathrm{ADF}$ program. Radii of anions and cations have been computed according to the procedure presented in ref 38 to reproduce the solvation energy of the cation.

2.1. Bonding Energy Analysis. We defined the energy of formation of the rosette according to eq 1

$$
\Delta E_{\mathrm{f}}=E_{\mathrm{R} @ \mathrm{~A}}-n \times E_{\mathrm{m}}-E_{\mathrm{A}}
$$

where $E_{\mathrm{R} @ \mathrm{~A}}$ is the energy of the rosette with a specific symmetry (either $C_{2 h}$ or $C_{2}$ ), $n$ is the number of monomers (either 6 or 12), $E_{\mathrm{m}}$ is the energy of the most stable tautomer conformation of the isolated monomer (without symmetry restrictions), and $E_{\mathrm{A}}$ is the energy of the isolated ion $\left(\mathrm{A}=\mathrm{X}^{-}\right.$, $\left.\mathrm{Y}^{+}\right)$; therefore, this equation expresses the relative stability of the rosettes. It should be mentioned that eq 1 implicitly considers the tautomerization energy $\Delta E_{\text {taut }}=E_{\mathrm{m}}^{*}-E_{\mathrm{m}}{ }^{41}$ as shown in Scheme 3. The bonding energy is defined as

$$
\Delta E_{\text {bond }}^{C_{\text {sym }}}=E_{\mathrm{R} @ \mathrm{~A}}-n \times E_{\mathrm{m}}^{*}-E_{\mathrm{A}} ; \quad \text { with } \mathrm{A}=\mathrm{X}^{-} / \mathrm{Y}^{+}
$$

here, $E_{\mathrm{m}}^{*}$ is the energy of the isolated tautomer without symmetry restrictions (see also Scheme 3 ). The superscript 
Scheme 3. Partition of the Formation Energy of Rosettes with $C_{2 h}$ Symmetry (Monomers are Indicated by Hexagons)

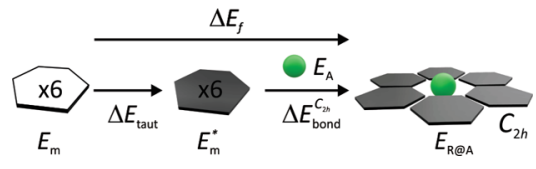

$C_{\text {sym }}$ is either $C_{2 h}$ or $C_{2}$ symmetry. Then, the overall bonding energy is made up of two major components

$$
\Delta E_{\text {bond }}^{C_{\text {sym }}}=\Delta E_{\text {prep }}+\Delta E_{\text {int }}
$$

The preparation energy $\Delta E_{\text {prep }}$ is the amount of energy required to deform the separate tautomers from their equilibrium structure to the geometry that they acquire in the rosette. The interaction energy $\Delta E_{\text {int }}$ corresponds to the actual energy change when the prepared units are combined to form the rosettes.

All interaction energy terms were examined in the framework of the Kohn-Sham molecular orbital model using quantitative energy decomposition analysis ${ }^{51-54}$ (EDA) into electrostatic interaction, Pauli-repulsive orbital interactions, and attractive orbital interactions

$$
\Delta E_{\text {int }}=\Delta V_{\text {elstat }}+\Delta E_{\text {Pauli }}+\Delta E_{\text {oi }}+\Delta E_{\text {disp }}
$$

The term $\Delta V_{\text {elstat }}$ corresponds to the classical electrostatic interaction between the unperturbed charge distributions of the prepared (i.e., deformed) units and is usually attractive.
The Pauli repulsion $\Delta E_{\text {Pauli }}$ comprises the destabilizing interactions between occupied orbitals and is responsible for any steric repulsion. The orbital interaction $\Delta E_{\mathrm{oi}}$ accounts for charge transfer (i.e., donor-acceptor interactions between occupied orbitals on one moiety with unoccupied orbitals of the other, including the HOMO-LUMO interactions) and polarization (empty/occupied orbital mixing on one fragment due to the presence of another fragment). The term $\Delta E_{\text {disp }}$ accounts for the dispersion corrections. The orbital interaction energy can be further decomposed into the contributions from each irreducible representation $\Gamma$ of the interacting system (eq $5)$. In the case of structures with planar symmetry, the orbital interaction is decomposed in $\sigma$ and $\pi$ contributions, which allows for separation of charge transfer (CT) in the $\sigma$ electronic system and polarization in the $\pi$ electronic system. $^{31,55}$

$$
\Delta E_{\mathrm{oi}}=\Delta E_{\sigma}+\Delta E_{\pi}
$$

\section{RESULTS AND DISCUSSION}

3.1. Rosettes with Central Ion. In this section, we address the situation in a surface environment, under the constraint of $C_{2 h}$ symmetry, and the capacity of the systems to coordinate anions or cations.

3.2. Structure and Relative Stabilities. We have already established that, among all tautomers, $\mathrm{M}_{6}$ and $a-\mathrm{AM}_{6}^{\prime}$ are the most stable rosettes both in the gas phase and in water. ${ }^{41}$ As

\begin{tabular}{|c|c|c|c|c|c|c|c|c|}
\hline rosette & ion & $\Delta E_{\mathrm{f}}^{b}$ & $\Delta E_{\text {bond }}^{C_{2 h}}$ & $\Delta E_{\text {coor }}{ }^{d}$ & $\Delta E_{\mathrm{HB}}^{e}$ & $\Delta E_{\text {int }}^{f}$ & $\Delta E_{\mathrm{f}}^{\mathrm{wg}}$ & $\Delta E_{\text {bond }}^{\mathrm{w}} h$ \\
\hline \multirow[t]{4}{*}{$\mathrm{M}_{6}$} & no ion & -79.3 & -79.3 & 0.0 & -79.3 & -86.8 & -44.3 & -44.3 \\
\hline & $\mathrm{Cl}^{-}$ & -143.6 & -143.6 & -69.1 & -74.5 & -153.5 & -53.1 & -53.1 \\
\hline & $\mathrm{Br}^{-}$ & -140.9 & -140.9 & -65.6 & -75.3 & -150.5 & -53.4 & -53.4 \\
\hline & $\mathrm{I}^{-}$ & -136.4 & -136.4 & -60.0 & -76.4 & -145.6 & -57.2 & -57.2 \\
\hline \multirow[t]{4}{*}{$\mathrm{M}_{6}^{\prime}$} & no ion & -36.3 & -180.1 & 0.0 & -180.1 & -204.7 & 1.6 & -77.3 \\
\hline & $\mathrm{Cl}^{-}$ & -81.2 & -224.9 & -50.2 & -174.8 & -257.2 & -2.9 & -81.8 \\
\hline & $\mathrm{Br}^{-}$ & -78.5 & -222.2 & -47.0 & -175.2 & -252.9 & -2.6 & -81.5 \\
\hline & $\mathrm{I}^{-}$ & -73.9 & -217.6 & -42.1 & -175.5 & -245.7 & -5.4 & -84.3 \\
\hline \multirow[t]{4}{*}{$\mathrm{M}_{6}^{\prime \prime}$} & no ion & -13.3 & -178.9 & 0.0 & -178.9 & -212.4 & 16.6 & -74.7 \\
\hline & $\mathrm{Cl}^{-}$ & -86.3 & -251.8 & -78.7 & -173.1 & -289.7 & 5.1 & -86.2 \\
\hline & $\mathrm{Br}^{-}$ & -82.4 & -248.0 & -73.6 & -174.4 & -284.9 & 5.2 & -86.2 \\
\hline & $\mathrm{I}^{-}$ & -75.8 & -241.3 & -65.7 & -175.6 & -276.8 & 2.1 & -89.2 \\
\hline \multirow[t]{4}{*}{$a-\mathrm{AM}_{6}$} & no ion & -101.5 & -101.5 & 0.0 & -101.5 & -120.7 & -23.3 & -67.9 \\
\hline & $\mathrm{Na}^{+}$ & -163.3 & -163.3 & -66.5 & -96.8 & -185.5 & -28.9 & -73.5 \\
\hline & $\mathrm{K}^{+}$ & -157.9 & -157.9 & -60.8 & -97.1 & -179.7 & -31.4 & -76.0 \\
\hline & $\mathrm{Rb}^{+}$ & -158.1 & -158.1 & -60.5 & -97.6 & -179.6 & -34.6 & -79.2 \\
\hline \multirow[t]{4}{*}{$a-\mathrm{AM}_{6}^{\prime}$} & no ion & -128.1 & -141.8 & 0.0 & -141.8 & -161.1 & -63.8 & -63.8 \\
\hline & $\mathrm{Na}^{+}$ & -198.0 & -211.8 & -79.4 & -132.4 & -238.5 & -67.5 & -67.5 \\
\hline & $\mathrm{K}^{+}$ & -192.7 & -206.5 & -72.3 & -134.2 & -232.3 & -70.4 & -70.4 \\
\hline & $\mathrm{Rb}^{+}$ & -192.7 & -206.5 & -71.4 & -135.1 & -232.0 & -73.3 & -73.3 \\
\hline \multirow[t]{4}{*}{$b-\mathrm{AM}_{6}$} & no ion & -81.8 & -85.5 & 0.0 & -85.5 & -101.1 & -15.3 & -60.0 \\
\hline & $\mathrm{Cl}^{-}$ & -165.9 & -165.9 & -88.9 & -77.1 & -187.0 & -29.0 & -73.7 \\
\hline & $\mathrm{Br}^{-}$ & -161.5 & -161.5 & -83.5 & -78.0 & -181.8 & -28.3 & -73.0 \\
\hline & $\mathrm{I}^{-}$ & -153.8 & -153.8 & -75.2 & -78.6 & -173.1 & -29.9 & -74.6 \\
\hline \multirow[t]{4}{*}{$b-\mathrm{AM}_{6}^{\prime}$} & no ion & -84.6 & -163.1 & 0.0 & -163.1 & -188.8 & -40.5 & -62.6 \\
\hline & $\mathrm{Cl}^{-}$ & -170.4 & -248.8 & -92.2 & -156.7 & -280.6 & -54.2 & -76.2 \\
\hline & $\mathrm{Br}^{-}$ & -166.0 & -244.5 & -86.3 & -158.2 & -275.3 & -53.9 & -76.0 \\
\hline & $\mathrm{I}^{-}$ & -158.5 & -237.0 & -77.4 & -159.7 & -266.4 & -56.6 & -78.6 \\
\hline
\end{tabular}
shown in Table 1 , the formation energies suggest, again, that

Table 1. Analysis of the Interaction Energies (in kcal mol ${ }^{-1}$ ) of Rosettes with $C_{2 h}$ Symmetry ${ }^{a}$

${ }^{a}$ ZORA-BLYP-D3(BJ)/TZ2P level of theory. ${ }^{b}$ Energy of formation in the gas phase. ${ }^{c}$ Bonding energy. ${ }^{d}$ Coordination energy. ${ }^{e}$ Hydrogen bond energy (eq 6). ${ }^{f}$ Interaction energy (eq 3). ${ }^{g}$ Energy of formation in water. ${ }^{h}$ Bonding energy with $C_{2 h}$ symmetry in water. 
Table 2. Geometrical Parameters (in $\AA$ ) of Single Rosettes with $C_{2 h}$ symmetry $^{a}$

\begin{tabular}{|c|c|c|c|c|c|c|c|}
\hline \multirow[b]{2}{*}{ rosette } & \multirow[b]{2}{*}{ ion } & \multicolumn{3}{|c|}{ gas phase } & \multicolumn{3}{|c|}{ water } \\
\hline & & $d_{\mathrm{i}}(\mathrm{D} \cdots \mathrm{A})^{b}$ & $\mathrm{~d}_{\mathrm{o}}(\mathrm{D} \cdots \mathrm{A})^{c}$ & $d_{\text {cavity }}{ }^{d}$ & $d_{\mathrm{i}}(\mathrm{D} \cdots \mathrm{A})$ & $d_{\mathrm{o}}(\mathrm{D} \cdots \mathrm{A})$ & $d_{\text {cavity }}$ \\
\hline \multirow[t]{4}{*}{$\mathrm{M}_{6}$} & empty & 2.95 & 2.97 & 7.71 & 2.97 & 2.98 & 7.66 \\
\hline & $\mathrm{Cl}^{-}$ & 2.91 & 2.92 & 7.43 & 2.94 & 2.95 & 7.50 \\
\hline & $\mathrm{Br}^{-}$ & 2.92 & 2.93 & 7.50 & 2.95 & 2.96 & 7.55 \\
\hline & $\mathrm{I}^{-}$ & 2.94 & 2.96 & 7.62 & 2.97 & 2.98 & 7.65 \\
\hline \multirow[t]{4}{*}{$\mathrm{M}_{6}^{\prime}$} & empty & 2.81 & 2.84 & 7.44 & 2.84 & 2.86 & 7.45 \\
\hline & $\mathrm{Cl}^{-}$ & 2.74 & 2.80 & 7.39 & 2.82 & 2.85 & 7.43 \\
\hline & $\mathrm{Br}^{-}$ & 2.75 & 2.81 & 7.47 & 2.82 & 2.85 & 7.50 \\
\hline & $\mathrm{I}^{-}$ & 2.77 & 2.83 & 7.59 & 2.83 & 2.87 & 7.61 \\
\hline \multirow[t]{4}{*}{$\mathrm{M}_{6}^{\prime \prime}$} & empty & 2.80 & 2.80 & 7.46 & 2.83 & 2.83 & 7.46 \\
\hline & $\mathrm{Cl}^{-}$ & 2.79 & 2.79 & 7.17 & 2.81 & 2.82 & 7.32 \\
\hline & $\mathrm{Br}^{-}$ & 2.80 & 2.80 & 7.26 & 2.82 & 2.83 & 7.38 \\
\hline & $\mathrm{I}^{-}$ & 2.81 & 2.82 & 7.41 & 2.83 & 2.84 & 7.50 \\
\hline \multirow[t]{4}{*}{$a-\mathrm{AM}_{6}$} & empty & 2.82 & 2.82 & 6.98 & 2.80 & 2.82 & 7.08 \\
\hline & $\mathrm{Na}^{+}$ & 2.73 & 2.77 & 6.82 & 2.77 & 2.79 & 6.90 \\
\hline & $\mathrm{K}^{+}$ & 2.74 & 2.78 & 6.83 & 2.76 & 2.79 & 6.89 \\
\hline & $\mathrm{Rb}^{+}$ & 2.74 & 2.78 & 6.87 & 2.76 & 2.79 & 6.91 \\
\hline \multirow[t]{4}{*}{$a-\mathrm{AM}_{6}^{\prime}$} & empty & 2.84 & 2.81 & 7.61 & 2.89 & 2.83 & 7.38 \\
\hline & $\mathrm{Na}^{+}$ & 2.81 & 2.78 & 6.97 & 2.85 & 2.80 & 7.11 \\
\hline & $\mathrm{K}^{+}$ & 2.82 & 2.79 & 7.05 & 2.86 & 2.81 & 7.19 \\
\hline & $\mathrm{Rb}^{+}$ & 2.82 & 2.79 & 7.09 & 2.86 & 2.80 & 7.14 \\
\hline \multirow[t]{4}{*}{$b-\mathrm{AM}_{6}$} & empty & 2.83 & 2.85 & 7.53 & 2.83 & 2.83 & 7.22 \\
\hline & $\mathrm{Cl}^{-}$ & 2.81 & 2.81 & 7.07 & 2.81 & 2.81 & 7.12 \\
\hline & $\mathrm{Br}^{-}$ & 2.83 & 2.83 & 7.16 & 2.82 & 2.83 & 7.19 \\
\hline & $\mathrm{I}^{-}$ & 2.85 & 2.86 & 7.31 & 2.85 & 2.86 & 7.32 \\
\hline \multirow[t]{4}{*}{$b-\mathrm{AM}_{6}^{\prime}$} & empty & 2.77 & 2.81 & 7.42 & 2.81 & 2.88 & 7.37 \\
\hline & $\mathrm{Cl}^{-}$ & 2.76 & 2.80 & 7.08 & 2.79 & 2.86 & 7.21 \\
\hline & $\mathrm{Br}^{-}$ & 2.77 & 2.81 & 7.18 & 2.80 & 2.87 & 7.29 \\
\hline & $\mathrm{I}^{-}$ & 2.79 & 2.83 & 7.34 & 2.82 & 2.89 & 7.43 \\
\hline
\end{tabular}

${ }^{a}$ ZORA-BLYP-D3(BJ)/TZ2P level of theory. ${ }^{b}$ Average inner hydrogen bond distance $\mathrm{D}(\mathrm{H}) \cdots \mathrm{A} .{ }^{c}$ Average outer hydrogen bond distance $\mathrm{D}(\mathrm{H}) \cdots \mathrm{A}$. ${ }^{d}$ Average diameter taken between the nitrogen/oxygen atoms which define the cavity.

the most stable systems with $C_{2 h}$ symmetry are $\mathrm{M}_{6} @ \mathrm{X}^{-}$and $a$ $\mathrm{AM}_{6}^{\prime} @ \mathrm{Y}^{+}$, either in the gas phase or in water (see Schemes 1 and 2). The energies of formation amount between -136 and $-144 \mathrm{kcal} \mathrm{mol}^{-1}$ for $\mathrm{M}_{6} @ \mathrm{X}^{-}$and between -192 and -198 $\mathrm{kcal} \mathrm{mol}^{-1}$ for $a-\mathrm{AM}_{6}^{\prime} @ \mathrm{Y}^{+}$(see Table 1). With regards to the other tautomers, the ions add an extra stabilization factor, but it is not enough to stabilize the rosettes, neither in gas phase nor water. Rosettes with $\mathrm{Cl}^{-}$and $\mathrm{Na}^{+}$show the greatest $\Delta E_{\mathrm{f}}$ in the gas phase. However, because of solvation effects, ${ }^{33,56}$ the affinity for ions changes in water, which results in larger bonding and formation energies for systems with $\mathrm{I}^{-}$and $\mathrm{Rb}^{+}$. Even though AM was shown to be a superior building block to M, with or without solvation, ${ }^{41}$ we show herein two new positive sides of these self-assembling molecules. While $M$ coordinates only anions, the selectivity of AM toward anions or cations could be tuned by selecting an appropriate salt.

Table 2 collects the parameters that define the structural effects of the ions, that is, the hydrogen bond distances and the size of the cavity. The most remarkable consequence of introducing them in the center is the shrinkage of the central cavity in the planar rosette. This means that upon addition of $\mathrm{Cl}^{-}$or $\mathrm{Na}^{+}$, the size of the cavity and hydrogen bond distances are reduced. With the subsequent addition of the bigger ions $\left(\mathrm{X}^{-}=\mathrm{Br}^{-}, \mathrm{I}^{-} ; \mathrm{Y}^{+}=\mathrm{K}^{+}, \mathrm{Rb}^{+}\right)$, those distances gradually increase until they reach almost the size of the empty scaffold. This phenomenon has also been previously observed for guanine quadruplexes (GQs). ${ }^{33,34}$
Both formation and bonding energies reveal that the ions add an extra stabilization factor to the system, so they are interacting with the functional groups of the cavity. Therefore, we have partitioned the overall bonding energy of the complexes (eq 2) into two main components: the coordination energy $\Delta E_{\text {coor, }}$ which is straight forwardly related to the recognition process, and the hydrogen bond energy $\Delta E_{\mathrm{HB}}$ (eq $6)$.

$$
\begin{aligned}
\Delta E_{\text {bond }}^{C_{2 h}} & =\left(E_{\mathrm{R} @ \mathrm{~A}}-E_{\mathrm{R}}^{\mathrm{R} @ \mathrm{~A}}-E_{\mathrm{A}}\right)+\left(E_{\mathrm{R}}^{\mathrm{R} @ \mathrm{~A}}-6 \times E_{\mathrm{m}}^{*}\right) \\
& =\Delta E_{\text {coor }}+\Delta E_{\mathrm{HB}}
\end{aligned}
$$

In this equation, $E_{\mathrm{R} @ \mathrm{~A}}$ is the energy of the rosette@ion coordination complex and $E_{\mathrm{R}}^{\mathrm{R} @ \mathrm{~A}}$ is the energy of the empty rosette in the structure of the rosette@ion coordination complex, so the superscript indicates the considered geometry. All bonding energy terms are also shown in Table 1 .

Our partitioning scheme reveals that introducing either anions or cations in the cavity weakens the hydrogen bonds within the rosettes (see $\Delta E_{\mathrm{HB}}$ values in Table 1). Note that the weakening of these hydrogen bonds goes with the shortenings of the $\mathrm{D}(\mathrm{H}) \cdots \mathrm{A}$ distances (see Table 2 ). The biggest ions ( $\mathrm{I}^{-}$ and $\mathrm{Rb}^{+}$) are less distortive but the coordination energy is lower. In addition, this approach let us discriminate which system will perform better for a specific ion. For instance, the formation energies suggest that AM will recognize only cations, but it is worth pointing out the differences in anion recognition between $\mathrm{M}$ and AM. From Table 1, one can see that $b-\mathrm{AM}_{6}$ 
Table 3. EDA of $\Delta E_{\text {coor }}$ (in kcal mol ${ }^{-1}$ ) and Charge Transfer of Rosettes with $C_{2 h}$ symmetry in the Gas Phase ${ }^{a}$

\begin{tabular}{|c|c|c|c|c|c|c|c|c|}
\hline \multirow[b]{2}{*}{ rosette } & \multirow[b]{2}{*}{ ion } & \multirow[b]{2}{*}{$\Delta E_{\text {coor }}{ }^{b}$} & \multirow[b]{2}{*}{$\Delta V_{\text {elstat }}$} & \multirow[b]{2}{*}{$\Delta E_{\text {Pauli }}$} & \multicolumn{2}{|c|}{$\Delta E_{\mathrm{oi}}$} & \multirow[b]{2}{*}{$\Delta E_{\text {disp }}$} & \multirow[b]{2}{*}{$P_{\text {virtuals }}{ }^{c}$} \\
\hline & & & & & $\Delta E_{\sigma}$ & $\Delta E_{\pi}$ & & \\
\hline \multirow[t]{3}{*}{$\mathrm{M}_{6}$} & $\mathrm{Cl}^{-}$ & -69.1 & -51.9 & 14.7 & -18.2 & -8.0 & -5.9 & 0.24 \\
\hline & $\mathrm{Br}^{-}$ & -65.6 & -53.7 & 22.3 & -18.8 & -7.7 & -7.7 & 0.22 \\
\hline & $\mathrm{I}^{-}$ & -60.0 & -56.1 & 34.7 & -20.5 & -7.5 & -10.5 & 0.28 \\
\hline \multirow[t]{3}{*}{$\mathrm{M}_{6}^{\prime}$} & $\mathrm{Cl}^{-}$ & -50.2 & -33.0 & 15.9 & -18.6 & -8.4 & -6.1 & 0.19 \\
\hline & $\mathrm{Br}^{-}$ & -47.0 & -35.6 & 23.7 & -19.0 & -8.1 & -8.0 & 0.20 \\
\hline & $\mathrm{I}^{-}$ & -42.1 & -39.5 & 36.5 & -20.4 & -7.8 & -10.9 & 0.22 \\
\hline \multirow[t]{3}{*}{$\mathrm{M}_{6}^{\prime \prime}$} & $\mathrm{Cl}^{-}$ & -78.7 & -63.9 & 21.7 & -21.6 & -8.2 & -6.6 & 0.26 \\
\hline & $\mathrm{Br}^{-}$ & -73.6 & -65.8 & 31.5 & -22.9 & -7.9 & -8.6 & 0.24 \\
\hline & $\mathrm{I}^{-}$ & -65.7 & -67.8 & 46.7 & -25.4 & -7.6 & -11.6 & 0.33 \\
\hline \multirow[t]{3}{*}{$a-\mathrm{AM}_{6}$} & $\mathrm{Na}^{+}$ & -66.5 & -38.3 & 0.7 & -10.1 & -6.9 & -11.9 & 0.06 \\
\hline & $\mathrm{K}^{+}$ & -60.8 & -38.6 & 2.9 & -9.9 & -6.9 & -8.2 & 0.05 \\
\hline & $\mathrm{Rb}^{+}$ & -60.5 & -39.0 & 4.9 & -10.0 & -6.9 & -9.5 & 0.07 \\
\hline \multirow[t]{3}{*}{$a-\mathrm{AM}_{6}^{\prime}$} & $\mathrm{Na}^{+}$ & -79.4 & -52.0 & 0.6 & -9.2 & -7.3 & -11.4 & 0.06 \\
\hline & $\mathrm{K}^{+}$ & -72.3 & -51.2 & 2.2 & -8.8 & -7.2 & -7.4 & 0.03 \\
\hline & $\mathrm{Rb}^{+}$ & -71.4 & -47.3 & 3.6 & -8.8 & -7.1 & -8.2 & 0.04 \\
\hline \multirow[t]{3}{*}{$b-\mathrm{AM}_{6}$} & $\mathrm{Cl}^{-}$ & -88.9 & -75.5 & 24.4 & -22.0 & -9.0 & -6.9 & 0.26 \\
\hline & $\mathrm{Br}^{-}$ & -83.5 & -77.7 & 35.2 & -23.4 & -8.7 & -8.8 & 0.26 \\
\hline & $\mathrm{I}^{-}$ & -75.2 & -80.3 & 51.5 & -26.1 & -8.4 & -11.9 & 0.35 \\
\hline \multirow[t]{3}{*}{$b-\mathrm{AM}_{6}^{\prime}$} & $\mathrm{Cl}^{-}$ & -92.2 & -79.0 & 25.0 & -22.8 & -8.4 & -6.9 & 0.26 \\
\hline & $\mathrm{Br}^{-}$ & -86.3 & -80.4 & 35.3 & -24.2 & -8.1 & -8.9 & 0.26 \\
\hline & $\mathrm{I}^{-}$ & -77.4 & -81.6 & 50.6 & -26.7 & -7.7 & -11.9 & 0.37 \\
\hline
\end{tabular}

${ }^{a}$ ZORA-BLYP-D3(BJ)/TZ2P level of theory. ${ }^{b}$ Coordination energy (eq 6). ${ }^{c} P_{\text {virtuals }}$ is the sum of the gross Mulliken population of the LUMO till $\mathrm{LUMO}+10$. For systems with $\mathrm{X}^{-}$, LUMOs correspond to $\mathrm{N}-\mathrm{H}$ antibonding orbitals. For systems with $\mathrm{Y}^{+}$, LUMOs correspond to the metal.

and $b$ - $\mathrm{AM}_{6}^{\prime}$ coordinate anions more strongly than $\mathrm{M}_{6}$. In the case of iodide, for example, the formation energy of $b-\mathrm{AM}_{6} @ \mathrm{I}^{-}$ is $-17.4 \mathrm{kcal} \mathrm{mol}{ }^{-1}$ stronger than $\mathrm{M}_{6} @ \mathrm{I}^{-}$, and $b-\mathrm{AM}_{6}^{\prime} @ \mathrm{I}^{-}$is also $-22.1 \mathrm{kcal} \mathrm{mol}{ }^{-1}$ stronger than $\mathrm{M}_{6} @ \mathrm{I}^{-}$(see also $\Delta E_{\text {coor }}$ values in Table 1 ). In addition, the formation energies in water are larger for $b-\mathrm{AM}_{6}$ and $b$ - $\mathrm{AM}_{6}^{\prime}$. Therefore, we show again the superior capacity of AM for designing new supramolecular systems, but with the ability to recognize anions and cations. In this framework, a conceivable alternative to this structure could be the isocytosine rosette ${ }^{57}$ because they share the same molecular skeleton and might also show cooperativity.

3.2.1. Energy Decomposition Analysis. The nature of the interactions was evaluated by an energy decomposition of each interaction energy term. Values for $\Delta E_{\text {coor }}$ are collected in Table 3, and values for $\Delta E_{\mathrm{HB}}$ are collected in Table S1. This analysis reveals that, in all cases, the coordination is mostly electrostatic in nature, providing around $60 \%$ of all attractive interactions. Nevertheless, the orbital component $\Delta E_{\mathrm{oi}}$, which constitutes of mixing of the occupied and unoccupied orbitals on one fragment due to the presence of the other and CT interactions between the two fragments, contributes around $30 \%$ and together with the dispersion correction (around $10 \%)$, the three components explain the attractive nature of the ion recognition.

The existence of a charge transfer component in the orbital interactions can be observed with gross Mulliken population of the lowest unoccupied molecular orbitals (LUMOs), and they are also shown in Table 3. These populations confirm that halide ions transfer electronic density to the antibonding unoccupied orbitals of the $\mathrm{N}-\mathrm{H}$ moieties. However, for the interaction between the metal cation and the donating orbitals of the rosettes, we observe that the electron population of the metal cations is rather poor. Figure 1 shows the orbitals involved in these interactions for $\mathrm{M}$ and $\mathrm{AM}$ rosettes. As can be seen in Figure 1, the LUMO of $\mathrm{M}_{6}$ that receives electronic

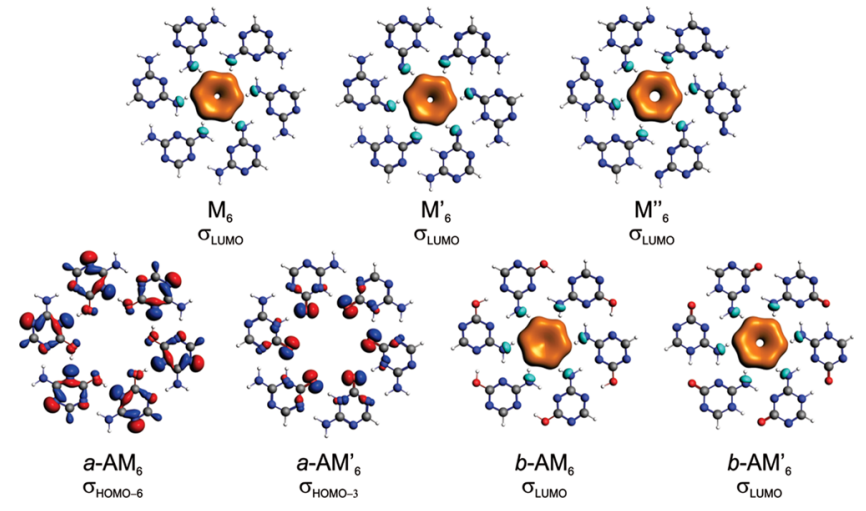

Figure 1. Highest occupied and lowest unoccupied orbitals of $M$ and AM rosettes contribute to the orbital interactions with either the halide anion or metal cation.

density from $\mathrm{X}^{-}$is entirely localized at the center of the rosette. This picture supports the fact that $\mathrm{M}$ and its tautomers have a strong capacity to recognize anions when the rosette is formed. The same can be seen for the $a-\mathrm{AM}_{6}$ and $a-\mathrm{AM}_{6}^{\prime}$ systems, in which all of the oxygen lone pairs $\left(\sigma_{\mathrm{HOMO}-6}\right.$ and $\sigma_{\mathrm{HOMO}-3}$, respectively) could donate electronic density to the metal. Nevertheless, these orbitals do not play a key role in the coordination. The highest unoccupied orbitals of $a-\mathrm{AM}_{6}$ and $a$ $\mathrm{AM}_{6}^{\prime}$ rosettes lose just 0.01 electrons, and there are no significant orbital overlaps between the metal cation and the $\sigma_{\mathrm{HOMO}-6}$ and $\sigma_{\mathrm{HOMO}-3}$ orbitals. Therefore, in order to dissect the nature of the coordination, we studied two reduced systems: a-AM@ $\mathrm{Na}^{+}$and $a-\mathrm{AM}^{\prime} @ \mathrm{Na}^{+}$dimers with the geometry they acquire in the rosettes. Interestingly, we found out that the orbital interactions of the systems with metal cations are caused predominantly by polarization as the CT interaction between the two fragments $\left(\sigma_{\mathrm{LP}} \rightarrow \sigma_{\mathrm{Na}^{+}}^{*}\right)$ is 
Table 4. Analysis of the Bonding Energies (in kcal mol ${ }^{-1}$ ) of Stacked Rosettes with $C_{2}$ Symmetry ${ }^{a}$

\begin{tabular}{|c|c|c|c|c|c|c|c|c|c|}
\hline complex & ion & $\Delta E_{\mathrm{f}}^{b}$ & $\Delta E_{\text {bond }^{c}}^{C_{2}}$ & $\Delta E_{\text {coor }}{ }^{d}$ & $\Delta E_{\text {stack }}^{e}$ & $\Delta E_{\mathrm{HB}}^{f}$ & $\Delta E_{\text {int }}^{g}$ & $\Delta E_{\mathrm{f}}^{\mathrm{w} h}$ & $\Delta E_{\text {bond }}^{\mathrm{w}}{ }^{i}$ \\
\hline \multirow[t]{4}{*}{$\mathrm{M}_{12}$} & no ion & -209.6 & -209.6 & 0.0 & -52.8 & -156.8 & -228.3 & -131.3 & -131.3 \\
\hline & $\mathrm{Cl}^{-}$ & -291.3 & -291.3 & -91.5 & -47.7 & -152.1 & -308.9 & -140.7 & -140.7 \\
\hline & $\mathrm{Br}^{-}$ & -290.1 & -290.1 & -89.9 & -47.7 & -152.5 & -307.5 & -144.7 & -144.7 \\
\hline & $\mathrm{I}^{-}$ & -288.5 & -288.5 & -87.4 & -47.7 & -153.4 & -305.8 & -152.1 & -152.1 \\
\hline \multirow[t]{4}{*}{$\mathrm{M}_{12}^{\prime}$} & no ion & -128.3 & -415.8 & 0.0 & -56.8 & -359.0 & -467.1 & -40.6 & -198.4 \\
\hline & $\mathrm{Cl}^{-}$ & -185.9 & -473.4 & -64.4 & -55.7 & -353.3 & -533.2 & -44.0 & -201.8 \\
\hline & $\mathrm{Br}^{-}$ & -184.6 & -472.1 & -62.9 & -55.7 & -353.5 & -531.2 & -47.4 & -205.2 \\
\hline & $\mathrm{I}^{-}$ & -182.8 & -470.3 & -60.6 & -55.8 & -354.0 & -528.0 & -53.8 & -211.6 \\
\hline \multirow[t]{4}{*}{$\mathrm{M}_{12}^{\prime \prime}$} & no ion & -85.7 & -416.8 & 0.0 & -59.6 & -357.1 & -489.9 & -12.0 & -194.7 \\
\hline & $\mathrm{Cl}^{-}$ & -175.5 & -506.5 & -103.2 & -51.9 & -351.5 & -581.3 & -22.7 & -205.3 \\
\hline & $\mathrm{Br}^{-}$ & -173.8 & -504.9 & -100.7 & -52.0 & -352.2 & -578.8 & -26.7 & -209.3 \\
\hline & $\mathrm{I}^{-}$ & -171.0 & -502.1 & -96.4 & -52.6 & -353.1 & -574.6 & -34.4 & -217.0 \\
\hline \multirow[t]{4}{*}{$a-\mathrm{AM}_{12}$} & no ion & -250.8 & -250.8 & 0.0 & -48.8 & -202.0 & -291.3 & -87.8 & -177.0 \\
\hline & $\mathrm{Na}^{+}$ & -338.0 & -338.0 & -95.3 & -44.1 & -198.6 & -391.6 & -97.3 & -186.5 \\
\hline & $\mathrm{K}^{+}$ & -330.5 & -330.5 & -88.0 & -44.1 & -198.3 & -384.1 & -103.2 & -192.3 \\
\hline & $\mathrm{Rb}^{+}$ & -328.8 & -328.8 & -83.3 & -45.9 & -199.6 & -372.6 & -108.5 & -197.6 \\
\hline \multirow[t]{4}{*}{$a-\mathrm{AM}_{12}^{\prime}$} & no ion & -307.2 & -327.2 & 0.0 & -44.7 & -282.6 & -367.4 & -162.5 & -162.5 \\
\hline & $\mathrm{Na}^{+}$ & -398.6 & -418.7 & -100.0 & -43.2 & -275.4 & -466.8 & -164.9 & -164.9 \\
\hline & $\mathrm{K}^{+}$ & -396.9 & -417.0 & -92.5 & -43.8 & -280.7 & -462.0 & -172.3 & -172.3 \\
\hline & $\mathrm{Rb}^{+}$ & -394.2 & -414.3 & -94.4 & -43.4 & -276.5 & -461.7 & -173.8 & -173.8 \\
\hline \multirow[t]{4}{*}{$b-\mathrm{AM}_{12}$} & no ion & -216.4 & -216.4 & 0.0 & -51.3 & -165.0 & -264.1 & -71.4 & -160.6 \\
\hline & $\mathrm{Cl}^{-}$ & -321.2 & -321.2 & -118.7 & -43.8 & -158.7 & -363.4 & -88.4 & -177.6 \\
\hline & $\mathrm{Br}^{-}$ & -319.0 & -319.0 & -115.6 & -44.2 & -159.2 & -360.1 & -91.1 & -180.2 \\
\hline & $\mathrm{I}^{-}$ & -315.1 & -315.1 & -110.4 & -44.8 & -160.0 & -355.5 & -97.5 & -186.7 \\
\hline \multirow[t]{4}{*}{$b-\mathrm{AM}_{12}^{\prime}$} & no ion & -236.6 & -386.1 & 0.0 & -56.5 & -329.6 & -440.7 & -117.8 & -161.9 \\
\hline & $\mathrm{Cl}^{-}$ & -340.7 & -490.2 & -119.7 & -50.0 & -320.5 & -550.1 & -131.7 & -175.7 \\
\hline & $\mathrm{Br}^{-}$ & -339.0 & -488.5 & -117.0 & -50.6 & -321.0 & -547.9 & -134.8 & -178.8 \\
\hline & $\mathrm{I}^{-}$ & -336.1 & -485.6 & -112.2 & -51.8 & -321.6 & -543.9 & -142.1 & -186.2 \\
\hline
\end{tabular}

${ }^{a}$ ZORA-BLYP-D3(BJ)/TZ2P level of theory. ${ }^{b}$ Formation energy (eq 1). ${ }^{c}$ Bonding energy with $C_{2}$ symmetry (eq 2 ). ${ }^{d}$ Coordination. ${ }^{e}$ Stacking bond energy. ${ }^{f}$ Hydrogen bond energy (eq 7). ${ }^{g}$ Overall interaction energy. ${ }^{h}$ Formation energy in water (COSMO). ${ }^{i}$ Bonding energy in water (COSMO).

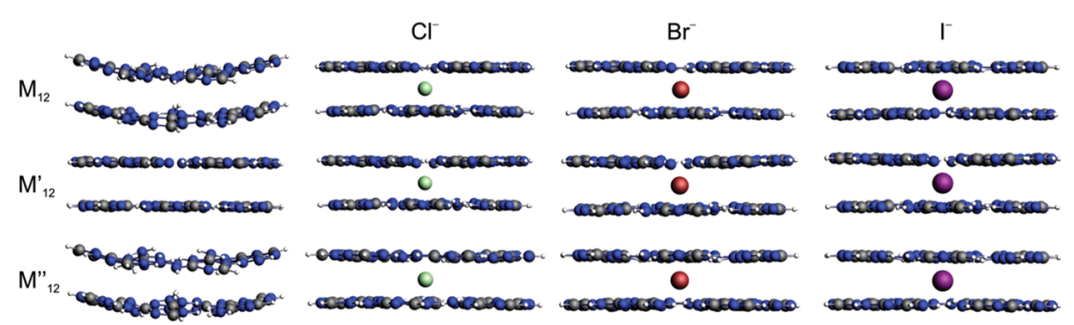

Figure 2. Structures of $M$ stacked rosettes in the gas phase optimized at ZORA-BLYP-D3(BJ)/TZ2P with $C_{2}$ symmetry.

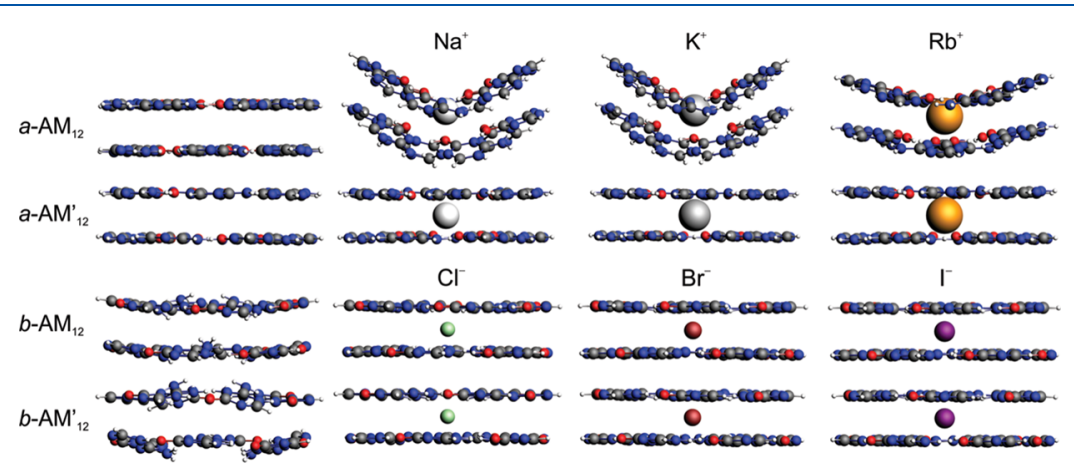

Figure 3. Structures of AM stacked rosettes in the gas phase optimized at ZORA-BLYP-D3(BJ)/TZ2P with $C_{2}$ symmetry.

negligible. Removal of the virtual orbitals of the metal cation showed that the orbital interaction did not decrease much (see Table S2). This means that the metal cation does not receive charge donation and just polarizes the triazine moiety. Contrarily to this behavior, the anion coordination is governed by the $\sigma_{\mathrm{LP}} \rightarrow \sigma_{\mathrm{N}-\mathrm{H}}^{*} \mathrm{CT}$ interaction. Figure S2 shows the $\sigma_{\mathrm{N}-\mathrm{H}}^{*}$ 


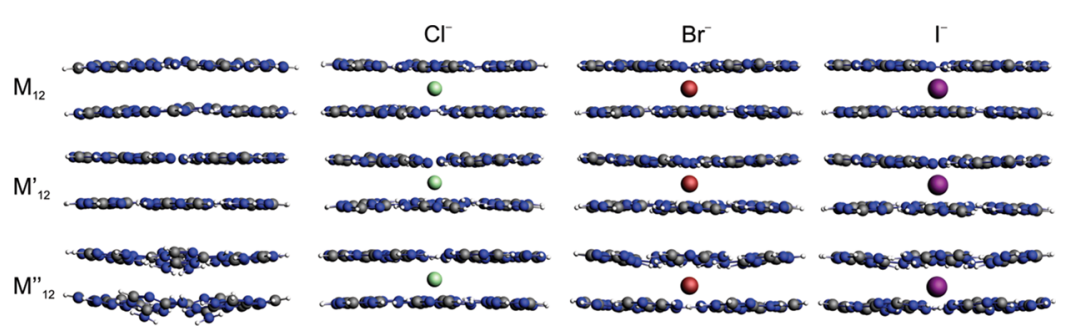

Figure 4. Structures of $M$ stacked rosettes in water optimized at ZORA-BLYP-D3(BJ)/TZ2P with $C_{2}$ symmetry.

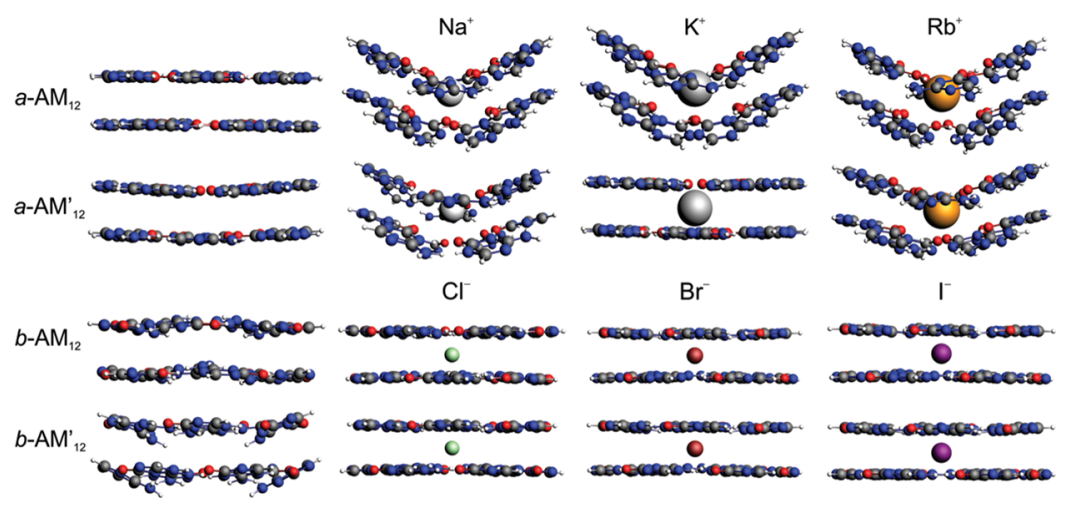

Figure 5. Structures of AM stacked rosettes in water optimized at ZORA-BLYP-D3(BJ)/TZ2P with $C_{2}$ symmetry.

antibonding orbitals along with their Gross populations. Here, the removal of the virtual orbitals from the aminotriazines (Table S3) showed a large decrease in orbital interactions as the donor-acceptor interaction was excluded. (For more details, see Supporting Information Discussion 1 and ref 25).

3.3. Stacked Rosettes. 3.3.1. Structure and Relative Stabilities. Our next step in the investigation of the ion recognition was to introduce the stacking arrangement of the rosettes. In this arrangement, the trend in the stability does not change. As shown in Table 4, the formation energies indicate that $\mathrm{M}_{12} @ \mathrm{X}^{-}$and $a-\mathrm{AM}_{12}^{\prime} @ \mathrm{Y}^{+}$will predominate both in the gas phase and in water. The systems with the greatest formation and bonding energies in water are those, again, for $\mathrm{I}^{-}$and $\mathrm{Rb}^{+}$.

Figures 2 and 3 show the molecular structures in the gas phase of $\mathrm{M}$ and $\mathrm{AM}$ stacked rosettes, respectively. A glance at these figures immediately reveals that the empty systems adopt an almost planar stacking. Besides, both anions and cations induce structural changes on the rosettes, which can be associated with a templation effect. This means that after introducing the ion in the empty scaffold, some structures experience a structural rearrangement. In most cases, the systems become more planar; specially $\mathrm{M}_{12}, \mathrm{M}_{12}{ }^{\prime \prime}, b-\mathrm{AM}_{12}$, and $b-\mathrm{AM}_{12}^{\prime}$. When introducing anions in the cavity, all of the amine groups pyramidalize in such a way that all hydrogen atoms point toward the anion. Contrarily, when introducing cations within $a-\mathrm{AM}_{12}$, the system adopts a saddle or $\mathrm{V}$ shape. The energy required to turn this last structure into a planar one again (planarization energy) was estimated to be around $4 \mathrm{kcal}$ $\mathrm{mol}^{-1}$. This value suggests that the transition from bend to planar is very shallow; thus, within a more realistic system with more layers, such as a nanowire, the rosettes may adopt a planar structure. It is also important to keep in mind that the global minima of $a-\mathrm{AM}_{6}$ and $a-\mathrm{AM}_{6}^{\prime}$ rosettes are not fully planar, and they adopt saddle-like shapes ${ }^{41}$ (see also Supporting Information Discussion 2).
To look further into the structures, we measured the average inner and outer hydrogen-bonding distances, and the size of the cavities (see Table S4). The general trend is the same as that in the planar rosettes: the average diameter of the cavities decreases upon addition of $\mathrm{Cl}^{-} / \mathrm{Na}^{+}$, and then, it gradually increases with the successive larger ions.

Next, we analyzed the systems in an aqueous environment, as shown in Figures 4 and 5. In general, the complexes retain their original gas-phase structures, except the $a-\mathrm{AM}_{12}^{\prime}$ system. This aggregate adopts almost the same structure as that of its imidate-like counterpart, for $\mathrm{Na}^{+}$and $\mathrm{Rb}^{+}$, but not for $\mathrm{K}^{+}$. Therefore, we tackled the query where does this behavior come from. If we look at the size of the cavity, when adding $\mathrm{Na}^{+}$to the empty scaffold, the rosette is contracted and then with $\mathrm{K}^{+}$, it is expanded again, and finally, it is slightly contracted with $\mathrm{Rb}^{+}$(see $d_{\text {cavity }}$ values in Table S4). To shed light on these structures, we analyzed the preparation energy by our approach in a previous work, ${ }^{33}$ which consists in partitioning the preparation energy into the preparation of the hydrogen bond energy $\Delta E_{\text {prep,HB}}$, and the preparation of the stacking $\Delta E_{\text {prep,stack }}($ see Table S5). Both components are the smallest for $a-\mathrm{AM}_{12}^{\prime} @ \mathrm{~K}^{+}$with values of, respectively, 2.7 and $1.5 \mathrm{kcal} \mathrm{mol}^{-1}$, which means that $\mathrm{K}^{+}$is less distorting for this system; thus, it fits geometrically best.

Finally, as it was suggested in the previous section and providing the fact that $\mathrm{M}_{6}$ and $a-\mathrm{AM}_{6}^{\prime}$ are the most stable rosettes, we propose that both compounds could form a potent mixture for dual-ion pair receptors (see Figure S4 in the Supporting Information). Alike the ditopic ion pair receptor based on guanine and adenine quartets, which was reported by Lippert et al., ${ }^{38}$ we propose herein a stacked complex formed by one layer of $\mathrm{M}_{6} @ \mathrm{Cl}^{-}$and another one of $a-\mathrm{AM}_{6}^{\prime} @ \mathrm{Na}^{+}$to form a dual-ion pair receptor: $a-\mathrm{AM}_{6}^{\prime}[\mathrm{NaCl}] \mathrm{M}_{6}$.

3.3.2. Partitioning of the Bond Energy. The partitioning of the bond energy allows us to explore the consequences of introducing ions within the cavity. With that in mind, the bonding energy in the stacking environment (eq 2) can also be 
decomposed into three main components: coordination energy $\Delta E_{\text {coor }}$, stacking energy $\Delta E_{\text {stack, }}$ and hydrogen-bond energy $\Delta E_{\mathrm{HB}}$, according to eq 7 (see also Scheme 4).

$$
\begin{aligned}
\Delta E_{\text {bond }}^{C_{2}}= & \left(E_{\mathrm{R}[\mathrm{A}] \mathrm{R}}-E_{\mathrm{R}[] \mathrm{R}}^{\mathrm{R}[\mathrm{R}}-E_{\mathrm{A}}\right) \\
& +\left(E_{\mathrm{R}[] \mathrm{R}}^{\mathrm{R}[\mathrm{A}] \mathrm{R}}-2 \times E_{\mathrm{R}}^{\mathrm{R}[\mathrm{A}] \mathrm{R}}\right) \\
& +\left[2\left(E_{\mathrm{R}}^{\mathrm{R}[\mathrm{A}] \mathrm{R}}-6 \times E_{\mathrm{m}}^{*}\right)\right] \\
= & \Delta E_{\text {coor }}+\Delta E_{\text {stack }}+\Delta E_{\mathrm{HB}}
\end{aligned}
$$

Scheme 4. Partitioning of the Bond Energy of the Stacked Rosettes

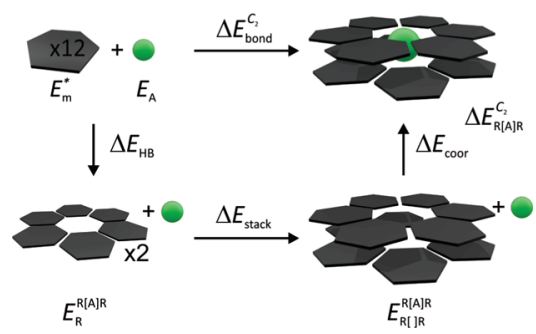

In these formulas, $E_{\mathrm{R}[\mathrm{A}] \mathrm{R}}$ is the energy of the stacked rosette with an interlayer ion, $E_{\mathrm{R}[] \mathrm{R}}$ is the energy of the empty scaffold, and the superscripts indicate the considered geometry. All these values, which are listed in Table 4, show that the stacking and the hydrogen bond energies are slightly weakened, and the coordination energy is almost an additional factor that is added to an empty system. When comparing the single rosettes with the stacked ones, the addition of a second rosette to the former system improves the coordination energy by around 25 to $45 \%$. For instance, the coordination energy for $\mathrm{M}$ goes from $-69.1 \mathrm{kcal} \mathrm{mol}^{-1}$ in $\mathrm{M}_{6} @ \mathrm{Cl}^{-}$to $-91.5 \mathrm{kcal} \mathrm{mol}^{-1}$ in the stack system (an increase of $32.4 \%$ ). In these stacked structures, AM still performs better than $\mathrm{M}$ to coordinate anions. Regarding the hydrogen bond energy $\Delta E_{\mathrm{HB}}$, this term is less weakened in the stacks than in the planar state; for example, two rosettes of $\mathrm{M}\left(2 \times \mathrm{M}_{6} @ \mathrm{Cl}^{-}\right)$gives $\Delta E_{\mathrm{HB}}=-149$ $\mathrm{kcal} \mathrm{mol}^{-1}$, while in the stacks $\left(\mathrm{M}_{12} @ \mathrm{Cl}^{-}\right)$, this value corresponds to $-152 \mathrm{kcal} \mathrm{mol}^{-1}$. In the case of $a-\mathrm{AM}_{12}^{\prime}$, the hydrogen bond energy of the stack is $10 \mathrm{kcal} \mathrm{mol}^{-1}$ more stable than in the planar arrangement.

3.3.3. Energy Decomposition Analysis. The nature of the coordination does not change in the stacks, and the trends are preserved. The average contributions to the attractive interactions are the same as those in the planar systems, that is, $60 \%$ electrostatic, $30 \%$ orbital, and $10 \%$ dispersive (see Table 5). Furthermore, as expected, the stacking energy is mostly dispersive in nature (see Table S6 in the Supporting Information).

Although the coordination energy $\Delta E_{\text {coor }}$ increases when the rosettes stack on top of each other, the charge transfer component $\left(P_{\text {virtuals }}\right)$ does not increase in this environment. The most representative orbitals are displayed in Figure 6. The presented orbitals provide a clear indication that the LUMO in $\mathrm{M}_{12}$, which receives charge donation from halides, is mostly localized at the center of the rosette and displaying a cylinderlike form. This is very interesting because in a pillar array, this orbital might be longitudinally localized such as in a coaxial wire. Hence, this suggests that the supramolecular wire could form an ionic channel to capture anions along its longitude.

In the systems with cations, the metal receives less charge donation than in the planar systems. At this point, we can invoke a very familiar system: the GQ. If we compare the $P_{\text {virtaul }}$ values of $a-\mathrm{AM}_{12}^{\prime} @ \mathrm{Y}^{+}(0.03,0.01$, and 0.01) with those obtained for GQ@Y $\mathrm{Y}^{+}(0.25,0.13$, and 0.15) for the same metals ${ }^{33}\left(\mathrm{Na}^{+}, \mathrm{K}^{+}\right.$and $\mathrm{Rb}^{+}$, respectively), it can be noticed that

\begin{tabular}{|c|c|c|c|c|c|c|c|}
\hline rosette & ion & $\Delta E_{\text {coor }}^{b}$ & $\Delta V_{\text {elstat }}$ & $\Delta E_{\text {Pauli }}$ & $\Delta E_{\mathrm{oi}}$ & $\Delta E_{\text {disp }}$ & $P_{\text {virtuals }}{ }^{c}$ \\
\hline \multirow[t]{3}{*}{$\mathrm{M}_{12}$} & $\mathrm{Cl}^{-}$ & -91.5 & -66.1 & 11.9 & -28.8 & -8.5 & 0.25 \\
\hline & $\mathrm{Br}^{-}$ & -89.9 & -69.3 & 19.5 & -28.5 & -11.6 & 0.23 \\
\hline & $\mathrm{I}^{-}$ & -87.4 & -74.6 & 34.0 & -30.1 & -16.7 & 0.23 \\
\hline \multirow[t]{3}{*}{$\mathbf{M}_{12}^{\prime}$} & $\mathrm{Cl}^{-}$ & -64.4 & -38.5 & 13.6 & -30.4 & -9.1 & 0.26 \\
\hline & $\mathrm{Br}^{-}$ & -62.9 & -42.4 & 22.1 & -30.2 & -12.4 & 0.20 \\
\hline & $\mathrm{I}^{-}$ & -60.6 & -49.1 & 38.1 & -31.9 & -17.8 & 0.27 \\
\hline \multirow[t]{3}{*}{$\mathrm{M}_{12}^{\prime \prime}$} & $\mathrm{Cl}^{-}$ & -103.2 & -78.5 & 16.4 & -31.5 & -9.7 & 0.28 \\
\hline & $\mathrm{Br}^{-}$ & -100.7 & -82.2 & 26.3 & -31.7 & -13.1 & 0.26 \\
\hline & $\mathrm{I}^{-}$ & -96.4 & -88.2 & 44.2 & -33.9 & -18.5 & 0.31 \\
\hline \multirow[t]{3}{*}{$a-\mathrm{AM}_{12}$} & $\mathrm{Na}^{+}$ & -95.3 & -53.3 & 0.8 & -22.4 & -20.4 & 0.07 \\
\hline & $\mathrm{K}^{+}$ & -88.0 & -54.0 & 3.2 & -22.6 & -14.7 & 0.03 \\
\hline & $\mathrm{Rb}^{+}$ & -83.3 & -51.2 & 3.9 & -20.4 & -15.6 & 0.03 \\
\hline \multirow[t]{3}{*}{$a-\mathrm{AM}_{12}^{\prime}$} & $\mathrm{Na}^{+}$ & -100.0 & -65.7 & 0.4 & -18.4 & -16.4 & 0.03 \\
\hline & $\mathrm{K}^{+}$ & -92.5 & -60.3 & 1.2 & -16.7 & -16.7 & 0.01 \\
\hline & $\mathrm{Rb}^{+}$ & -94.4 & -65.4 & 2.5 & -18.1 & -13.4 & 0.01 \\
\hline \multirow[t]{3}{*}{$b-\mathrm{AM}_{12}$} & $\mathrm{Cl}^{-}$ & -118.7 & -95.2 & 19.3 & -32.4 & -10.3 & 0.28 \\
\hline & $\mathrm{Br}^{-}$ & -115.6 & -99.6 & 30.7 & -33.0 & -13.8 & 0.26 \\
\hline & $\mathrm{I}^{-}$ & -110.4 & -106.3 & 51.0 & -35.6 & -19.4 & 0.31 \\
\hline \multirow[t]{3}{*}{$b-\mathrm{AM}_{12}^{\prime}$} & $\mathrm{Cl}^{-}$ & -119.7 & -95.7 & 17.0 & -31.3 & -9.8 & 0.25 \\
\hline & $\mathrm{Br}^{-}$ & -117.0 & -99.3 & 27.0 & -31.4 & -13.2 & 0.23 \\
\hline & $\mathrm{I}^{-}$ & -112.2 & -104.6 & 44.6 & -33.5 & -18.6 & 0.27 \\
\hline
\end{tabular}
the charge transfer component is superior for GQ. When analyzing the size of their cavities, as shown in Figure 7, the

Table 5. EDA of $\Delta E_{\text {coor }}$ (in kcal mol ${ }^{-1}$ ) and Charge Transfer of Stacked Rosettes with $C_{2}$ Symmetry in the Gas Phase ${ }^{a}$

${ }^{a}$ ZORA-BLYP-D3(BJ)/TZ2P level of theory. ${ }^{b}$ Coordination energy (eq 7). ${ }^{c} P_{\text {virtuals }}$ is the sum of the gross Mulliken population of the LUMO till $\mathrm{LUMO}+15$. For systems with $\mathrm{X}^{-}$, LUMOs correspond to the rosette scaffold. For systems with $\mathrm{Y}^{+}$, LUMOs correspond to the metal. 

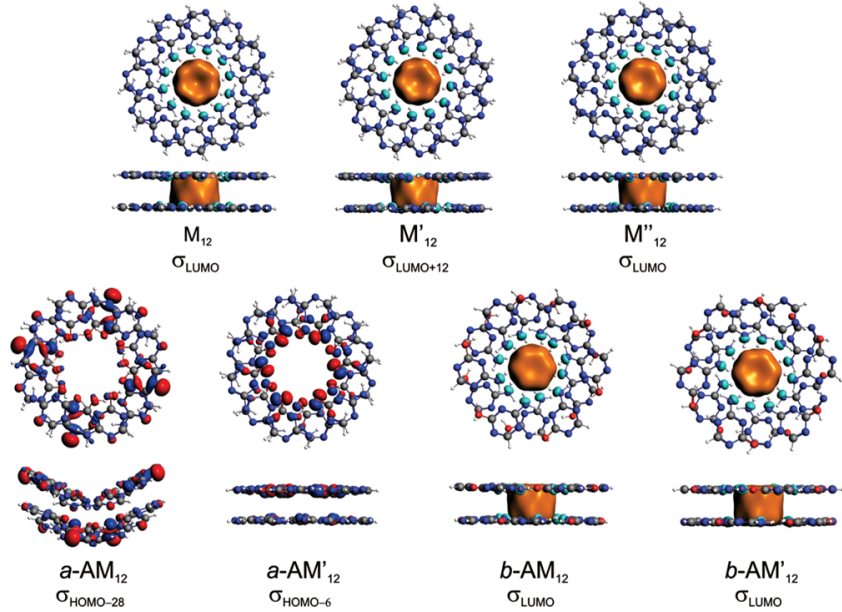

Figure 6. $\sigma_{\mathrm{LUMO}}$ and $\sigma_{\mathrm{HOMO}-6}$ orbitals of $\mathrm{M}_{12}$ and a-AM, respectively, that contribute to the orbital interactions with either the halides or metals.
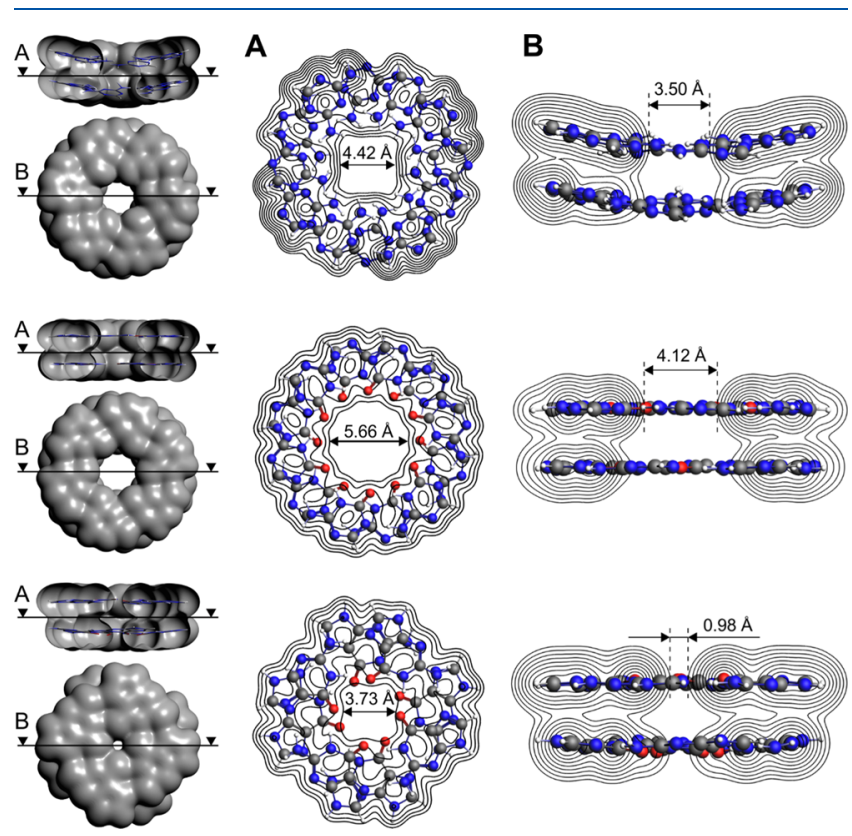

Figure 7. Longitudinal (A) and cross-sections (B) of electron density surfaces $\rho(r)$ (isosurface $\rho(r)=0.001$ a.u.). Top: $\mathrm{M}_{12}$, middle: $a$ $\mathrm{AM}_{12}^{\prime}$, and bottom: GQ. Computed at ZORA-BLYP-D3(BJ)/TZ2P in the gas phase. size of the pore is much larger in $a-\mathrm{AM}_{12}^{\prime}$. This difference in sizes leads to different orbital overlaps $\left(S^{2}\right)$ between the electron-donating and electron-accepting orbitals. For instance, the most important donor-acceptor interaction goes with a value of 0.019 for $S^{2}$ in GQ@ $@ \mathrm{Na}^{+}$, while for $a-\mathrm{AM}_{12}^{\prime} @ \mathrm{Na}^{+}, S^{2}$ amounts to 0.007 for the most important donor-acceptor interaction.

For a deeper understanding of the metal coordination, we have estimated the relevance of the donor-acceptor interactions between the cation and the stacked rosettes as well as the polarization within the stack of rosettes. To this aim, we performed computations that exclude polarization in the rosettes by removing all virtual orbitals of the stacked rosettes $\left(a-\mathrm{AM}_{12}\right.$ and $\left.a-\mathrm{AM}_{12}^{\prime}\right)$ in the complexes $a-\mathrm{AM}_{12} @ \mathrm{Y}^{+}$ and $a-\mathrm{AM}_{12}^{\prime} @ \mathrm{Y}^{+}$, that is, computations $\mathrm{C}=\mathrm{O}[\phi,-] \ldots$ $\mathrm{Y}^{+}\left[\phi, \phi^{*}\right]$. In addition, we blocked the $\sigma_{\mathrm{LP}} \rightarrow \sigma_{\mathrm{Y}^{+}}^{*}$ donoracceptor interaction by removing the virtuals of the metal, and the resulting orbital interactions $\left(\mathrm{C}=\mathrm{O}\left[\phi, \phi^{*}\right] \cdots \mathrm{Y}^{+}[\phi,-]\right)$ are displayed in Table 6. The orbital interaction in $a-\mathrm{AM}_{12} @ \mathrm{Na}^{+}$ amounts to $-22.4 \mathrm{kcal} \mathrm{mol}^{-1}$ (see Table 6) and drops to -4.2 $\mathrm{kcal} \mathrm{mol}^{-1}$ when the virtuals are removed from the rosette scaffold. The same happens for $a-\mathrm{AM}_{12}^{\prime} @ \mathrm{Na}^{+}$which goes from -18.4 to $-2.3 \mathrm{kcal} \mathrm{mol}^{-1}$. Furthermore, when the charge transfer between the cation and the stack of rosettes is blocked, the orbital contribution to the coordination energy is almost unaffected. As the only allowed orbital interaction (in the computations with the virtuals removed from the stacked rosettes) being the donor-acceptor interaction between the occupied orbitals of the stacked rosettes and the lowestunoccupied orbitals of the cation, we can conclude that polarization within the stacked rosettes because of the presence of the cation plays a dominant contribution to the orbital interaction energy. These results are in line with the values for the gross populations in Table 5 .

We also studied the anion coordination within the most stable systems with anions, that is, $\mathrm{M}_{12} @ \mathrm{X}^{-}$and $b-\mathrm{AM}_{12}^{\prime} @ \mathrm{X}^{-}$. When allowing only charge transfer interaction between the anion and the rosette scaffold, that is, $\mathrm{N}-\mathrm{H}\left[\phi, \phi^{*}\right] \cdots \mathrm{X}^{-}[\phi,-]$, our results (Table 7) showed that the anions do transfer electron density to the rosette scaffold through the set of $\sigma_{\mathrm{N}-\mathrm{H}}^{*}$ antibonding orbitals that form the cavity. Then, if we block the last process by switching of the virtual orbitals of the rosette scaffolds, the orbital interaction energy drops to a value that ranges from -1 to $-3 \mathrm{kcal} \mathrm{mol}^{-1}$. Thus, the charge transfer process overruled the anion coordination.

3.3.4. Gibbs Free Energy of Formation. At this stage, we have analyzed the bonding mechanism between ions and the stacked rosettes. For the self-assembly, we have computed the

Table 6. Orbital Interaction Energies $\left(\Delta E_{\mathrm{oi}}\right)\left(\mathrm{kcal} \mathrm{mol}^{-1}\right)$ for $a-\mathrm{AM}_{12} @ \mathrm{Y}^{+}$and $a-\mathrm{AM}_{12} @ \mathrm{Y}^{+}$with and without $\mathrm{CT}$ and Polarization $(\mathbf{P o l})^{a}$

$\begin{array}{llccc} & & \mathrm{C}=\mathrm{O}\left[\phi, \phi^{*}\right] \cdots \mathrm{Y}^{+}\left[\phi, \phi^{*}\right]^{b} & \mathrm{C}=\mathrm{O}[\phi,-] \cdots \mathrm{Y}^{+}\left[\phi, \phi^{*}\right]^{c} & \mathrm{C}=\mathrm{O}\left[\phi, \phi^{*}\right] \cdots \mathrm{Y}^{+}[\phi,-]^{d} \\ \text { rosette } & \mathrm{Y}^{+} & \mathrm{CT} \text { and Pol } & \text { only CT } & \text { only Pol } \\ a-\mathrm{AM}_{12} & \mathrm{Na}^{+} & -22.4 & -4.2 & -21.4 \\ & \mathrm{~K}^{+} & -22.6 & -4.0 & -21.3 \\ & \mathrm{Rb}^{+} & -20.4 & -3.8 & -19.2 \\ & \mathrm{Na}^{+} & -18.4 & -2.3 & -17.7 \\ & \mathrm{KM}_{12}^{\prime} & -16.7 & -2.0 & -16.0 \\ & \mathrm{Rb}^{+} & -18.1 & -2.5 & -17.3\end{array}$

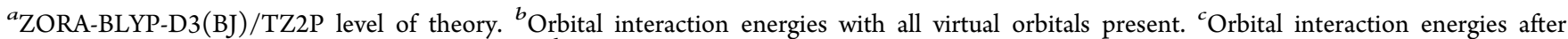
removal of virtual orbitals of the rosette scaffold. ${ }^{d}$ Orbital interaction energies after removal of virtual orbitals of the cation. 
Table 7. Orbital Interaction Energies $\left(\Delta E_{\mathrm{oi}}\right)\left(\mathrm{kcal} \mathrm{mol}^{-1}\right)$ for $a-\mathrm{AM}_{12} @ \mathrm{Y}^{+}$and $a-\mathrm{AM}_{12} @ \mathrm{Y}^{+}$with and without $\mathrm{CT}$ and Polarization $(\text { Pol })^{a}$

\begin{tabular}{|c|c|c|c|c|}
\hline & & $\mathrm{N}-\mathrm{H}\left[\phi, \phi^{*}\right] \cdots \mathrm{X}-\left[\phi, \phi^{*}\right]^{b}$ & $\mathrm{~N}-\mathrm{H}\left[\phi, \phi^{*}\right] \cdots \mathrm{X}^{-}[\phi,-]^{c}$ & $\mathrm{~N}-\mathrm{H}[\phi,-] \cdots \mathrm{X}^{-}\left[\phi, \phi^{*}\right]^{d}$ \\
\hline rosette & $\mathrm{X}^{-}$ & $\mathrm{CT}$ and Pol & only CT & only Pol \\
\hline \multirow[t]{3}{*}{$\mathrm{M}_{12}$} & $\mathrm{Cl}^{-}$ & -28.8 & -27.1 & -1.2 \\
\hline & $\mathrm{Br}^{-}$ & -28.5 & -26.9 & -1.7 \\
\hline & $\mathrm{I}^{-}$ & -30.1 & -28.4 & -2.3 \\
\hline \multirow[t]{3}{*}{$b-\mathrm{AM}_{12}^{\prime}$} & $\mathrm{Cl}^{-}$ & -31.3 & -29.6 & -1.6 \\
\hline & $\mathrm{Br}^{-}$ & -31.4 & -29.4 & -2.0 \\
\hline & $\mathrm{I}^{-}$ & -33.5 & -31.4 & -3.0 \\
\hline
\end{tabular}

${ }^{a}$ ZORA-BLYP-D3(BJ)/TZ2P level of theory. ${ }^{b}$ Orbital interaction energies with all virtual orbitals present. ${ }^{c}$ Orbital interaction energies after removal of virtual orbitals of the anion. ${ }^{d}$ Orbital interaction energies after removal of virtual orbitals of the rosette scaffold.

changes in Gibbs free energy of formation in water for the most stable complexes with and without $\mathrm{Cl}^{-}$and $\mathrm{Na}^{+}$, as shown in Table 8. Gibbs free energy values show that the

Table 8. Gibbs Free Energies (in kcal $\mathrm{mol}^{-1}$ ) for the Most Stable Rosettes with Chloride and Sodium Cations ${ }^{a}$

$\begin{array}{llcccc}\text { rosette } & \text { ion } & \Delta E_{\mathrm{f}} & \Delta G_{\mathrm{f}}^{b} & \Delta H_{\mathrm{f}}^{b} & -T \Delta S_{\mathrm{f}}^{b} \\ \mathrm{M}_{12} & \text { no ion } & -198.6 & -20.0 & -181.7 & 140.7 \\ & \mathrm{Cl}^{-} & -214.8 & -21.3 & -199.7 & 178.4 \\ a-\mathrm{AM}_{12}^{\prime} & \text { no ion } & -227.4 & -48.1 & -215.1 & 127.6 \\ & \mathrm{Na}^{+} & -233.3 & -43.1 & -222.3 & 179.2\end{array}$

${ }^{a}$ (ZORA-BLYP-D3(BJ)/DZP level of theory). ${ }^{b}$ Thermodynamic properties of formation in water.

formation in water is viable. A related case recently reported by Zaccaria and Fonseca Guerra ${ }^{34}$ has shown a $\Delta G_{\mathrm{f}}$ of $-45.3 \mathrm{kcal}$ $\mathrm{mol}^{-1}$ for a GQ with an interlayer $\mathrm{K}^{+}$at the same level of theory. This result, which is comparable to that of $a-\mathrm{AM}_{12}^{\prime} @$ $\mathrm{Na}^{+}$, suggest that the assembly could be experimentally feasible in water. Unlike the case of $\mathrm{GQ} @ \mathrm{~K}^{+}$which needs the cation to self-assemble, ${ }^{34}$ our rosettes show negative values for $\Delta G_{\mathrm{f}}$ even without the presence of the ions. Nevertheless, the monomers should be equipped with side chains to direct and improve the assembly, which is a current proceeding. Until now, stacked rosettes of melamine have never been obtained experimentally without any covalent modification. ${ }^{12,13,47}$

\section{CONCLUSIONS}

Our DFT-D calculations predict that $\mathrm{M}$ and AM rosettes can accommodate ions within their central cavities without further distortion. This is also possible in two different environments: in a layer, as it would be in a self-assembled monolayer, and in between two stacked rosettes, alike the naturally occurring GQs and nanowires. While $M$ can only recognize anions, AM rosettes could recognize both anions and cations. Therefore, one could control the ion recognition capability of ammeline with the appropriate selection of the salt. In addition, based on the formation energies, $\mathrm{M}$ and $\mathrm{AM}$ could constitute a potent binary mixture for dual-receptor strategies.

The energy of formation of the complexes consists of the tautomerization energy, the coordination energy, the hydrogen bond energy, and stacking energy. Our bonding analyses show that the coordination energy is essentially an additive factor to the empty systems. When going from single to stacked rosettes, the coordination energy can be enhanced from 25 up to $45 \%$. Furthermore, the nature of the anion recognition process was found to be dominated by electrostatic and donor-acceptor interactions between the occupied orbitals of the anion and the lowest unoccupied orbitals of the rosette that corresponds to antibonding orbitals on the $\mathrm{N}-\mathrm{H}$ groups. On the contrary, the coordination of the metals is dominated by electrostatic interaction and polarization within the rosettes. The metal cation receives almost no electronic charge from the rosettes because of the poor contribution of the occupied orbitals of carbonyl and hydroxy groups to the coordination.

Our computational results indicate that the most stable structures, in the gas phase and in water solution, are those of melamine in its amino-like form and ammeline in its amide-like form $\left(a-\mathrm{AM}^{\prime}\right)$. The Gibbs free energy of formation in water shows that the association into stacking arrangements is favorable, but the ions are not completely necessary for the assembly.

Finally, all of the ions have shown to organize the assemblies in a particular arrangement, with respect to the empty systems, both in the gas phase and in water. For instance, anions can induce planarity in melamine and ammeline, while cations induce $\mathrm{V}$ shape structures on empty scaffolds. Hence, not only could they be used as an external factor accompanying the assembly process but also they can be part of the final ensemble. These results are of importance for the rational design of self-assembling ionophore materials with tunable properties by the presence of different ions.

\section{ASSOCIATED CONTENT}

\section{Supporting Information}

The Supporting Information is available free of charge on the ACS Publications website at DOI: 10.1021/acs.jpcc.9b09366.

EDA analysis of rosettes with $C_{2 h}$ symmetry; discussion about the orbital contribution to the coordination energy; discussion of the saddle-shape structures; geometrical parameters of rosettes with $C_{2}$ symmetry (stack rosettes); partitioning of the preparation energy; structure of the dual-ion pair receptor $a-\mathrm{AM}_{6}^{\prime}[\mathrm{NaCl}] \mathrm{M}_{6}$; and EDA analysis of rosettes with $C_{2}$ symmetry (PDF)

\section{AUTHOR INFORMATION}

\section{Corresponding Author}

*E-mail: c.fonsecaguerra@vu.nl.

ORCID

Célia Fonseca Guerra: 0000-0002-2973-5321

Notes

The authors declare no competing financial interest.

\section{ACKNOWLEDGMENTS}

We thank the Netherlands Organization for Scientific Research (NWO/CW) for financial support. A.N.P. thanks the National 
Scientific and Technical Research Council (CONICET), Argentina, for a doctoral fellowship.

\section{REFERENCES}

(1) Whitesides, G. M.; Simanek, E. E.; Mathias, J. P.; Seto, C. T.; Chin, D.; Mammen, M.; Gordon, D. M. Noncovalent Synthesis: Using Physical-Organic Chemistry to Make Aggregates. Acc. Chem. Res. 1995, 28, 37-44.

(2) Prins, L. J.; Reinhoudt, D. N.; Timmerman, P. Noncovalent Synthesis Using Hydrogen Bonding. Angew. Chem., Int. Ed. 2001, 40, 2382-2426.

(3) Li, X.; Gao, Y.; Boott, C. E.; Winnik, M. A.; Manners, I. Noncovalent Synthesis of Supermicelles with Complex Architectures Using Spatially Confined Hydrogen-bonding Interactions. Nat. Commun. 2015, 6, 8127.

(4) Zhou, J.; Roembke, B. T.; Paragi, G.; Laguerre, A.; Sintim, H. O.; Fonseca Guerra, C.; Monchaud, D. Computational Understanding and Experimental Characterization of Twice-As-Smart Quadruplex Ligands as Chemical Sensors of Bacterial Nucleotide Second Messengers. Sci. Rep. 2016, 6, 33888.

(5) Paragi, G.; Kupihár, Z.; Endre, G.; Fonseca Guerra, C.; Kovács, L. The Evaluation of 5-amino- and 5-hydroxyuracil Derivatives as Potential Quadruplex-forming Agents. Org. Biomol. Chem. 2017, 15, 2174-2184.

(6) Stupp, S. I.; Palmer, L. C. Supramolecular Chemistry and SelfAssembly in Organic Materials Design. Chem. Mater. 2014, 26, 507518.

(7) Mayoral, M. J.; Bilbao, N.; González-Rodríguez, D. HydrogenBonded Macrocyclic Supramolecular Systems in Solution and on Surfaces. ChemistryOpen 2016, 5, 10-32.

(8) Beingessner, R. L.; Fan, Y.; Fenniri, H. Molecular and Supramolecular Chemistry of Rosette Nanotubes. RSC Adv. 2016, 6, 75820-75838.

(9) Adhikari, B.; Lin, X.; Yamauchi, M.; Ouchi, H.; Aratsu, K.; Yagai, $S$. Hydrogen-bonded Rosettes Comprising $\pi$-conjugated Systems as Building Blocks for Functional One-dimensional Assemblies. Chem. Commun. 2017, 53, 9663-9683.

(10) Diem, H.; Matthias, G.; Wagner, R. A. Amino Resins. Ullmann's Encyclopedia of Industrial Chemistry; Wiley-VCH Verlag GmbH \& Co. KGaA: Weinheim, Germany, 2010.

(11) Roy, B.; Bairi, P.; Nandi, A. K. Supramolecular Assembly of Melamine and its Derivatives: Nanostructures to Functional Materials. RSC Adv. 2014, 4, 1708-1734.

(12) Jonkheijm, P.; Miura, A.; Zdanowska, M.; Hoeben, F. J. M.; De Feyter, S.; Schenning, A. P. H. J.; De Schryver, F. C.; Meijer, E. W. $\pi$ Conjugated Oligo-(p-phenylenevinylene) Rosettes and Their Tubular Self-Assembly. Angew. Chem., Int. Ed. 2004, 43, 74-78.

(13) Maly, K. E.; Dauphin, C.; Wuest, J. D. Self-assembly of Columnar Mesophases from Diaminotriazines. J. Mater. Chem. 2006, 16, 4695-4700.

(14) SeethaLekshmi, S.; Guru Row, T. N. Propensity of Formation of Zipper Architecture vs. Lincoln log Arrangement in Solvated Molecular Complexes of Melamine with Hydroxybenzoic Acids. CrystEngComm 2011, 13, 4886-4894.

(15) Braml, N. E.; Sattler, A.; Schnick, W. Formation of Melamium Adducts by Pyrolysis of Thiourea or Melamine $/ \mathrm{NH}_{4} \mathrm{Cl}$ Mixtures. Chem.-Eur. J. 2012, 18, 1811-1819.

(16) Makowski, S. J.; Lacher, M.; Lermer, C.; Schnick, W. Supramolecular Hydrogen-bonded Structures Between Melamine and N-heterocycles. J. Mol. Struct. 2012, 1013, 19-25.

(17) Staniec, P. A.; Perdigão, L. M. A.; Rogers, B. L.; Champness, N. R.; Beton, P. H. Honeycomb Networks and Chiral Superstructures Formed by Cyanuric Acid and Melamine on $\mathrm{Au}(111)$. J. Phys. Chem. C 2007, 111, 886-893.

(18) Xu, W.; Dong, M.; Gersen, H.; Rauls, E.; Vázquez-Campos, S.; Crego-Calama, M.; Reinhoudt, D. N.; Stensgaard, I.; Laegsgaard, E.; Linderoth, T. R; et al. Cyanuric Acid and Melamine on $\mathrm{Au}(111)$ : Structure and Energetics of Hydrogen-Bonded Networks. Small 2007, $3,854-858$
(19) Silly, F.; Shaw, A. Q.; Castell, M. R.; Briggs, G. A. D.; Mura, M.; Martsinovich, N.; Kantorovich, L. Melamine Structures on the $\mathrm{Au}(111)$ Surface. J. Phys. Chem. C 2008, 112, 11476-11480.

(20) Mura, M.; Martsinovich, N.; Kantorovich, L. Theoretical Study of Melamine Superstructures and their Interaction with the $\mathrm{Au}(111)$ Surface. Nanotechnology 2008, 19, 465704.

(21) Zhang, H.-M.; Xie, Z.-X.; Long, L.-S.; Zhong, H.-P.; Zhao, W.; Mao, B.-W.; Xu, X.; Zheng, L.-S. One-Step Preparation of Large-Scale Self-Assembled Monolayers of Cyanuric Acid and Melamine Supramolecular Species on $\mathrm{Au}(111)$ Surfaces. J. Phys. Chem. C 2008, 112, 4209-4218.

(22) Katsonis, N.; Xu, H.; Haak, R. M.; Kudernac, T.; Tomović, Ž.; George, S.; Van der Auweraer, M.; Schenning, A. P. H. J.; Meijer, E. W.; Feringa, B. L.; et al. Emerging Solvent-Induced Homochirality by the Confinement of Achiral Molecules Against a Solid Surface. Angew. Chem., Int. Ed. 2008, 47, 4997-5001.

(23) Minoia, A.; Guo, Z.; Xu, H.; George, S. J.; Schenning, A. P. H. J.; Feyter, S. D.; Lazzaroni, R. Assessing the Role of Chirality in the Formation of Rosette-like Supramolecular Assemblies on Surfaces. Chem. Commun. 2011, 47, 10924-10926.

(24) Ciesielski, A.; Haar, S.; Paragi, G.; Kupihár, Z.; Kele, Z.; Masiero, S.; Fonseca Guerra, C.; Bickelhaupt, F. M.; Spada, G. P.; Kovács, L.; et al. Supramolecular H-bonded Porous Networks at Surfaces: Exploiting Primary and Secondary Interactions in a Bicomponent. Phys. Chem. Chem. Phys. 2013, 15, 12442-12446.

(25) Li, Y.; Zhao, K.; Yang, Y.; Deng, K.; Zeng, Q.; Wang, C. Functionalization of Two-Component Molecular Networks: Recognition of $\mathrm{Fe}^{3+}$. Nanoscale 2012, 4, 148-151.

(26) Kohlmeier, A.; Vogel, L.; Janietz, D. Multiple Hydrogen Bonded Mesomorphic Complexes Between Complementary 1,3,5triazine and Pyrimidine Derivatives. Soft Matter 2013, 9, 9476-9486.

(27) Niu, L.; Song, J.; Li, J.; Tao, N.; Lu, M.; Fan, K. Solvent Effects on the Gelation Performance of Melamine and 2-ethylhexylphosphoric Acid Mono-2-ethylhexyl Ester in Water-organic Mixtures. Soft Matter 2013, 9, 7780-7786.

(28) Schenning, A. P. H. J.; Jonkheijm, P.; Hoeben, F. J. M.; Van Herrikhuyzen, J.; Meskers, S. C. J.; Meijer, E. W.; Herz, L. M.; Daniel, C.; Silva, C.; Phillips, R. T.; et al. Towards Supramolecular Electronics. Synth. Met. 2004, 147, 43-48.

(29) Varghese, R.; George, S. J.; Ajayaghosh, A. Anion Induced Modulation of Self-assembly and Optical Properties in Urea Endcapped Oligo(p-phenylenevinylene)s. Chem. Commun. 2005, 0, 593595.

(30) Ciesielski, A.; Lena, S.; Masiero, S.; Spada, G. P.; Samorì, P. Dynamers at the Solid-Liquid Interface: Controlling the Reversible Assembly/Reassembly Process between Two Highly Ordered Supramolecular Guanine Motifs. Angew. Chem., Int. Ed. 2010, 49, 19631966.

(31) Fonseca Guerra, C.; Zijlstra, H.; Paragi, G.; Bickelhaupt, F. M. Telomere Structure and Stability: Covalency in Hydrogen Bonds, Not Resonance Assistance, Causes Cooperativity in Guanine Quartets. Chem.-Eur. J. 2011, 17, 12612-12622.

(32) Szolomájer, J.; Paragi, G.; Batta, G.; Guerra, C. F.; Bickelhaupt, F. M.; Kele, Z.; Pádár, P.; Kupihár, Z.; Kovács, L. 3-Substituted Xanthines as Promising Candidates for Quadruplex Formation: Computational, Synthetic and Analytical Studies. New J. Chem. 2011, 35, 476-482.

(33) Zaccaria, F.; Paragi, G.; Fonseca Guerra, C. The Role of Alkali Metal Cations in the Stabilization of Guanine Quadruplexes: Why $\mathrm{K}^{+}$ is the best. Phys. Chem. Chem. Phys. 2016, 18, 20895-20904.

(34) Zaccaria, F.; Fonseca Guerra, C. RNA vs DNA G-Quadruplex: The Origin of Increased Stability. Chem.-Eur. J. 2018, 24, 1631516322.

(35) Buhler, E.; Sreenivasachary, N.; Candau, S.-J.; Lehn, J.-M. Modulation of the Supramolecular Structure of G-Quartet Assemblies by Dynamic Covalent Decoration. J. Am. Chem. Soc. 2007, 129, $10058-10059$.

(36) Venkatesh, V.; Mishra, N. K.; Romero-Canelón, I.; Vernooij, R. R.; Shi, H.; Coverdale, J. P. C.; Habtemariam, A.; Verma, S.; Sadler, P. 
J. Supramolecular Photoactivatable Anticancer Hydrogels. J. Am. Chem. Soc. 2017, 139, 5656-5659.

(37) Kotlyar, A. B.; Borovok, N.; Molotsky, T.; Cohen, H.; Shapir, E.; Porath, D. Long, Monomolecular Guanine-Based Nanowires. Adv. Mater. 2005, 17, 1901-1905.

(38) van der Wijst, T.; Fonseca Guerra, C.; Swart, M.; Bickelhaupt, F. M.; Lippert, B. A Ditopic Ion-Pair Receptors Based on Stacked Nucleobase Quartets. Angew. Chem., Int. Ed. 2009, 48, 3285-3287.

(39) van der Wijst, T.; Lippert, B.; Swart, M.; Fonseca Guerra, C.; Bickelhaupt, F. M. Differential Stabilization of Adenine Quartets $\left(\mathrm{A}_{4}\right)$ by Anions and Cations. J. Biol. Inorg Chem. 2010, 15, 387-397.

(40) Paragi, G.; Kupihár, Z.; Guerra, C.; Bickelhaupt, F.; Kovács, L. Supramolecular Ring Structures of 7-methylguanine: A Computational Study of its Self-assembly and Anion Binding. Molecules 2012, $18,225-235$

(41) Petelski, A. N.; Fonseca Guerra, C. Designing Self-Assembled Rosettes: Why Ammeline is a Superior Building Block to Melamine. ChemistryOpen 2019, 8, 135-142.

(42) te Velde, G.; Bickelhaupt, F. M.; Baerends, E. J.; Fonseca Guerra, C.; van Gisbergen, S. J. A.; Snijders, J. G.; Ziegler, T. Chemistry with ADF. J. Comput. Chem. 2001, 22, 931-967.

(43) Baerends, E. J.; Ziegler, T.; Atkins, A. J.; Autschbach, J.; Baseggio, O.; Bashford, D.; Bérces, A.; Bickelhaupt, F. M.; Bo, C.; Boerrigter, P. M.; et al. ADF2014.01, SCM, Theoretical Chemistry; Vrije Universiteit: Amsterdam, The Netherlands, http://www.scm. com.

(44) Fonseca Guerra, C.; Bickelhaupt, F. M.; Snijders, J. G.; Baerends, E. J. Hydrogen Bonding in DNA Base Pairs: Reconciliation of Theory and Experiment. J. Am. Chem. Soc. 2000, 122, 4117-4128.

(45) Rehm, T. H.; Schmuck, C. Ion-pair Induced Self-assembly in Aqueous Solvents. Chem. Soc. Rev. 2010, 39, 3597.

(46) Ma, M.; Bong, D. Determinants of Cyanuric Acid and Melamine Assembly in Water. Langmuir 2011, 27, 8841-8853.

(47) Cafferty, B. J.; Gállego, I.; Chen, M. C.; Farley, K. I.; Eritja, R.; Hud, N. V. Efficient Self-Assembly in Water of Long Noncovalent Polymers by Nucleobase Analogues. J. Am. Chem. Soc. 2013, 135, 2447-2450.

(48) Klamt, A.; Schüürmann, G. COSMO: A New Approach to Dielectric Screening in Solvents with Explicit Expressions for the Screening Energy and its Gradient. J. Chem. Soc., Perkin Trans. 2 1993, 799-805.

(49) Klamt, A. Conductor-like Screening Model for Real Solvents: A New Approach to the Quantitative Calculation of Solvation Phenomena. J. Phys. Chem. 1995, 99, 2224-2235.

(50) Pye, C. C.; Ziegler, T. An Implementation of the Conductorlike Screening Model of Solvation Within the Amsterdam Density Functional Package. Theor. Chem. Acc. 1999, 101, 396-408.

(51) Bickelhaupt, F. M.; Baerends, E. J. Kohn-Sham Density Functional Theory: Predicting and Understanding Chemistry. In Reviews in Computational Chemistry; Lipkowitz, K. B., Boyd, D. B., Eds.; Wiley-VCH: New York, 2000; Vol. 15, pp 1-86.

(52) Ziegler, T.; Rauk, A. CO, CS, $\mathrm{N}_{2}, \mathrm{PF}_{3}$, and $\mathrm{CNCH}_{3}$ as $\sigma$ Donors and $\pi$ Acceptors. A Theoretical Study by the Hartree-FockSlater Transition-state Method. Inorg. Chem. 1979, 18, 1755-1759.

(53) Ziegler, T.; Rauk, A. Theoretical Study of the Ethylene-metal Bond in Complexes Between $\mathrm{Cu}^{+}, \mathrm{Ag}^{+}, \mathrm{Aul}^{+}, \mathrm{Pt}^{0}$ or $\mathrm{Pt}^{2+}$ and Ethylene, Based on the Hartree-Fock-Slater Transition-State Method. Inorg. Chem. 1979, 18, 1558-1565.

(54) Ziegler, T.; Rauk, A. On the Calculation of Bonding Energies by the Hartree Fock Slater Method. Theor. Chim. Acta 1977, 46, 110.

(55) Fonseca Guerra, C.; Bickelhaupt, F. M.; Snijders, J. G.; Baerends, E. J. The Nature of the Hydrogen Bond in DNA Base Pairs: the role of Charge Transfer and Resonance Assistance. Chem.-Eur. J. 1999, 5, 3581-3594.

(56) Gu, J.; Leszczynski, J. Origin of $\mathrm{Na}^{+} / \mathrm{K}^{+}$Selectivity of the Guanine Tetraplexes in Water: The Theoretical Rationale. J. Phys. Chem. A 2002, 106, 529-532.
(57) Ciesielski, A.; Colella, S.; Zalewski, L.; Bruchmann, B.; Samorì, P. Nanopatterning the Graphite Surface with Ordered Macrocyclic or Ribbon-like Assemblies of Isocytosine Derivatives: an STM Study. CrystEngComm 2011, 13, 5535-5537. 